\title{
Lithological and geomorphological indicators of glacial genesis in the upper Quaternary strata, Nadym River basin, Western Siberia
}

\author{
Oleg Sizov ${ }^{1}$, Anna Volvakh ${ }^{2}$, Anatoly Molodkov ${ }^{3}$, Andrey Vishnevskiy ${ }^{4}$, Andrey Soromotin ${ }^{5}$, and Evgeny Abakumov ${ }^{6}$ \\ ${ }^{1}$ Oil and Gas Research Institute, Russian Academy of Sciences, Moscow, Russia \\ ${ }^{2}$ Sobolev Institute of Geology and Mineralogy, Siberian Branch of Russian Academy of Sciences, Novosibirsk, Russia \\ ${ }^{3}$ Department of Geology, Tallinn University of Technology, Tallinn, Estonia \\ ${ }^{4}$ Department of Geology and Geophysics, Novosibirsk State University, Novosibirsk, Russia \\ ${ }^{5}$ Research Institute of Ecology and Natural Resource Management, Tyumen State University, Tyumen, Russia \\ ${ }^{6}$ Department of Applied Ecology, Saint-Petersburg State University, Saint Petersburg, Russia
}

Correspondence: Evgeny Abakumov (e.abakumov@spbu.ru)

Received: 12 November 2019 - Discussion started: 13 December 2019

Revised: 3 September 2020 - Accepted: 20 September 2020 - Published: 10 November 2020

\begin{abstract}
Analysing the genesis of Quaternary sediments is important for understanding the glaciation history and development of marine sediments in the northern part of Western Siberia. The problem is relevant since there is no consistent concept of the Quaternary sediment genesis in the north of Western Siberia. The formation of sediments is associated with marine, glacial and interglacial sedimentation conditions. The research objective is to identify the persistent features characterising the conditions of sedimentation and relief formation using the Nadym River basin as an example. The best method for studying this problem is a comprehensive analysis of the lithological, chronostratigraphic, petrographic and geomorphological studies of the Quaternary sediment upper strata. This study provides data from the analysis of the basic characteristics of quartz grains at the site. The rounding and morphology of the quartz grains provide evidence of possible glacial processing of some of the site strata. A petrographic study of selected boulder samples was performed. Some of them, by the shape and presence of striation, can be attributed to ice basins. The first use of a detailed digital elevation model applied to the study area made it possible to identify specific relief forms that could very likely be created during glaciations. Based on the analysis, we propose to consider the vast lake alluvial plains in the Nadym River basin as periglacial regions. This idea lays the lithological framework for understanding the reasons for the formation of the modern landscape structure. The materials and descriptions provided are of interest to researchers of
\end{abstract}

Quaternary sediments, topography, vegetation and soil cover, particularly researchers engaged in revising the history of the natural environment development in the north of Western Siberia.

\section{Introduction}

The history of geomorphological development in the northern part of Western Siberia was a subject of intensive discussion at the end of the 20th century. The stratigraphy of the Yenisey River estuary is a key factor of the Western Siberian lowland Quaternary evolution. Numerous examples of sedimentation alternation induced by various cover glaciations of different ages and thicknesses are presented. This series of sediments was used as a background for geological interpretation of the history of the Western Siberian lowland. The Q-43 national geological map of Russia for this region indicates the dominance of glacial and fluvioglacial types of the surface sediments (Alyavdin and Mokin, 1957). The possible existence of ice sheets and related permafrost sediments was identified as a key issue at the beginning of the systematic geological study of the north of Western Siberia in the 1960s. Some researchers (e.g. Svendsen et al., 2004) suggested that there were extensive glaciations that resulted in blocking the Yenisei, Pur, Taz and Nadym rivers at certain stages, leading to the formation of large glacier dammed lakes (Grosvald, 1999). 
Another point of view considers possible glaciation on the plain (e.g. Generalov, 1986). It explains why the landforms are a sequence of terraces formed by marine transgressions of various ages. There is also an opinion that the glaciation was localised in the form of ice caps on separate watersheds and that the river flows of the Ob, Yenisei and other rivers were unblocked (Velichko, 1987; Velichko et al., 1997). Bolshiyanov (2006) challenged this opinion and introduced the "passive glaciation" concept. In this context, it is assumed that the sea level fluctuations might have created extensive abrasion platforms. Another viewpoint suggests that the forms of relief which previously were regarded as glacial and fluvioglacial (moraines and eskers), did not originate from cover glaciations but resulted from erosion, abrasion and thermokarst outcrops associated with permafrost erosion and tectonic processes of the Late Pleistocene. It was suggested that isolated parts of Smarovskoye glaciation (MIS8, 300000 to 230000 years ago) existed in some areas of the Tyumen region combined with relics of ancient marine terraces (Lazukov, 1972). Later, there was a heated discussion in the Russian geology community regarding the nature of possible glaciations and sedimentation history of Western Siberia. It was suggested that glaciations extended up to Siberian ridges that continued as the ancient periglacial Mansyiskoye Lake (Grosvald, 1999). Bolshiyanov (2006) suggested that the glaciations were passive, without forming a discontinuous cover or preferential flow blocking in the area topography. At the same time, the abrasion relief with extended ledges was formed in the Late Pleistocene period. Finally, the Q-42-43 national geological map indicates that there is a combination of both terrestrial glacial and marine glacial sediments and numerous lake terraces in Western Siberia. Nowadays, the glacial sediments are excluded from the current version of the national geological map (Babushkin, 1995), which contradicts the interpretations by Astakhov et al. (2016) and Fredin et al. (2012). Currently, there is no uniform concept of the landforms genesis in Western Siberia. The basin of the Nadym River is regarded as most important for the Quaternary interpretation of the regional Pleistocene history. The topography and sediments of the Nadym River provide the most information for the study of glacial landforms. Many field investigations and remote-sensing operations were completed by multiple generations of researchers, providing a valuable baseline for future studies. The results of studying the Nadym River and adjacent areas, combined with other data, served as a basis for a classification of the Quaternary deposits in Western Siberia (Maslennikov, 1998; Sedov et al, 2016; Sheinkman et al, 2016; Rusakov et al, 2018). Nevertheless, the current geological map (Faibusovic and Abakumova, 2015) still has unresolved issues that are highlighted as new geological and geomorphological data are obtained.

The study objective is to summarise the results of detailed lithological, chronostratigraphic, petrographic and geomorphological studies conducted in the Nadym River basin, and

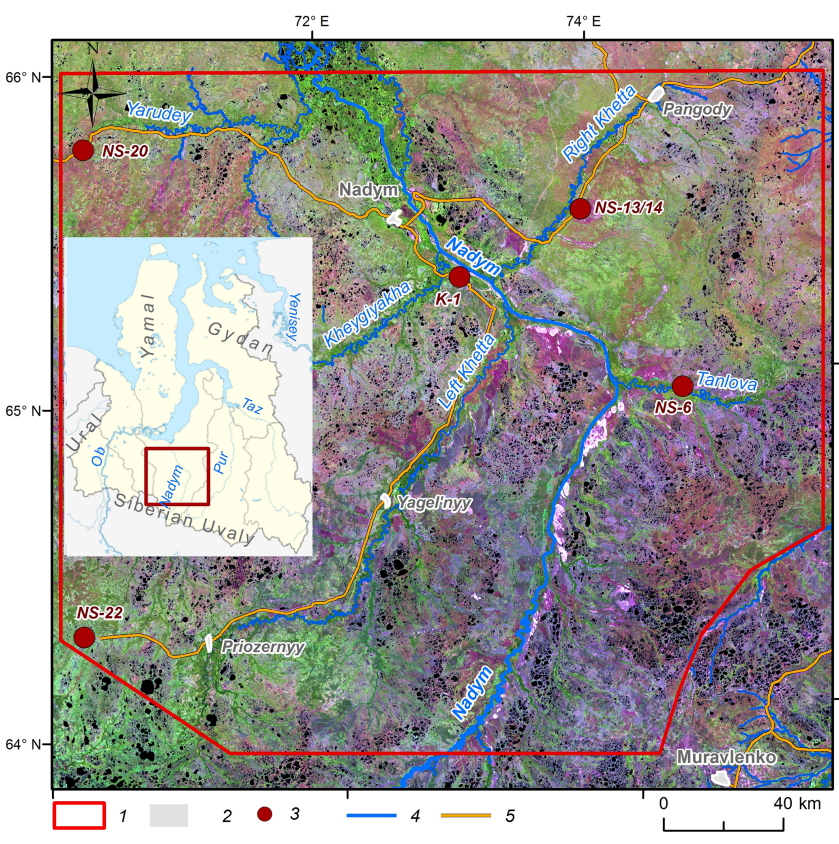

Figure 1. Overview map: (1) study area; (2) settlements; (3) studied and sampled locations; (4) waterways; (5) roads. Background image: Landsat 8, 2000.

to identify the origins of the key factors of sedimentation accumulation and topography.

\section{Materials and methods}

Fieldwork was conducted in 2016-2018 in the Nadym River basin, including the valleys of its main tributaries: Kheygiyaha, Yarudey, Tanlova, and Left and Right Khetta. The region is characterised by a moderate human-induced burden. There are main gas pipelines (Urengoy-Pomara-Uzhhorod, Nadym-Punga-Lower-Tura, etc.), high-voltage power transmission lines $(200,500 \mathrm{kV})$, an oil pipeline (Yarudeyskoe field CGS to Puryel OPS) and the Nadym-Yagelskoye asphalt road. The survey covered the natural exposures along riverbanks, walls of dry quarries located at the watersheds and river terrañes as the most informative terrain features. This paper is based on the results of detailed studies of the five most prominent stratigraphy sections of the upper part of Quaternary sediments (Fig. 1; Table 1). For clarity, the section coordinates, their locations, survey dates and the total thickness of the studied deposits are specified.

Samples for bulk chemical composition, grain size distribution, sand quartz grain morphoscopy and morphometry, as well as luminescent analysis of sandy textured particles of feldspars were taken from each specified layer of the studied sections in order to clarify the conditions of the sediment formation.

The bulk content of oxides was determined by the Xray fluorescence method at the Analytical Center for Multi- 
Table 1. Site properties.

\begin{tabular}{|c|c|c|c|c|c|c|}
\hline $\mathrm{N}$ & Coordinates $(\mathrm{N}, \mathrm{E})$ & $\begin{array}{r}\text { Top of } \\
\text { section } \\
\text { elevation, } \\
\text { (m a.s.l.) }\end{array}$ & Geogenic location & $\begin{array}{l}\text { Sampling } \\
\text { point } \\
\text { location }\end{array}$ & $\begin{array}{l}\text { Survey date } \\
\text { (dd.mm.yyyy) }\end{array}$ & $\begin{array}{r}\text { Thickness } \\
(\mathrm{m})\end{array}$ \\
\hline $\mathrm{K}-1$ & $\begin{array}{l}65.351044 \\
72.974041\end{array}$ & 24 & $\begin{array}{l}\text { Second above flood } \\
\text { plain terrace }\end{array}$ & Wall of quarry & 21.08 .2016 & 4.2 \\
\hline NS-6 & $\begin{array}{l}64.974808 \\
74.499714\end{array}$ & 44 & $\begin{array}{l}\text { Second above flood } \\
\text { plain terrace }\end{array}$ & River break & 18.08 .2017 & 9.5 \\
\hline NS-13/14 & $\begin{array}{l}65.52992 \\
73.875985\end{array}$ & 44.5 & Kamiform hill & $\begin{array}{l}\text { Top and slope } \\
\text { of hill }\end{array}$ & 22.08 .2017 & 5.1 \\
\hline NS-20 & $\begin{array}{l}65.778072 \\
70.29182\end{array}$ & 57 & Esker sediments & Wall of quarry & 11.08 .2018 & 16 \\
\hline NS-22 & $\begin{array}{l}64.31688 \\
70.232456\end{array}$ & 130 & Watershed & Wall of quarry & 13.08 .2018 & 1.5 \\
\hline
\end{tabular}

Elemental and Isotope Research, Siberian Branch (SB), Russian Academy of Sciences (RAS), Novosibirsk, Russia, and at the laboratory of the Institute for Physical, Chemical and Biological Problems of Soil Science (Pushchino, Russia). The grain size distribution was determined by conventional fractions separation (sieve analysis) of samples with the Fritsch Analysette 3 vibratory sieve shaker. The fractions were weighed with laboratory scales at $0.1 \mathrm{~g}$ accuracy. Seventeen samples from the sections NS-6 and NS-13/14 were analysed at the Laboratory of Ground Mechanics, Institute of Cryosphere of the Earth, Tyumen Research Center with the Mastersizer 3000E laser diffraction particle size analyser (Malvern Panalytical, Britain). Since different laboratories measured the granulometric composition, the figures for the lightest fractions are slightly different.

The Altami CM0870-T binocular microscope was used to study the quartz grains (50 grains per sample) taken from the coarse sand fraction. The grain surface morphology was studied with the JEOL JSM-6510LV scanning electron microscope (SEM) using the secondary electron image (SEI) at the Analytical Center for Multi-Elemental and Isotope Research, SB, RAS. According to the technique applied (Velichko and Timireva, 1995), the grain scale was determined using Rukhin (1969, Fig. 2) and Khabakov (1946), where 0 is an angular and IV is a perfectly rounded grain. The coefficients of roundness and the grades of dullness (Velichko and Timireva, 1995) were estimated for each sample. The dullness of the grains was determined visually as glossy (shiny), quarter-matte, half-matte and matte. The grain surface microrelief structure study was based on numerous published diagnostic features found in grains with various genesis and sediment accumulation conditions (e.g. Velichko and Timireva, 1995; Krinsley and Doornkamp, 2011; Vos et al., 2014; Woronko, 2016; Kalinska-Nartisa et al., 2017). The previous studies in Western Siberia that exam-

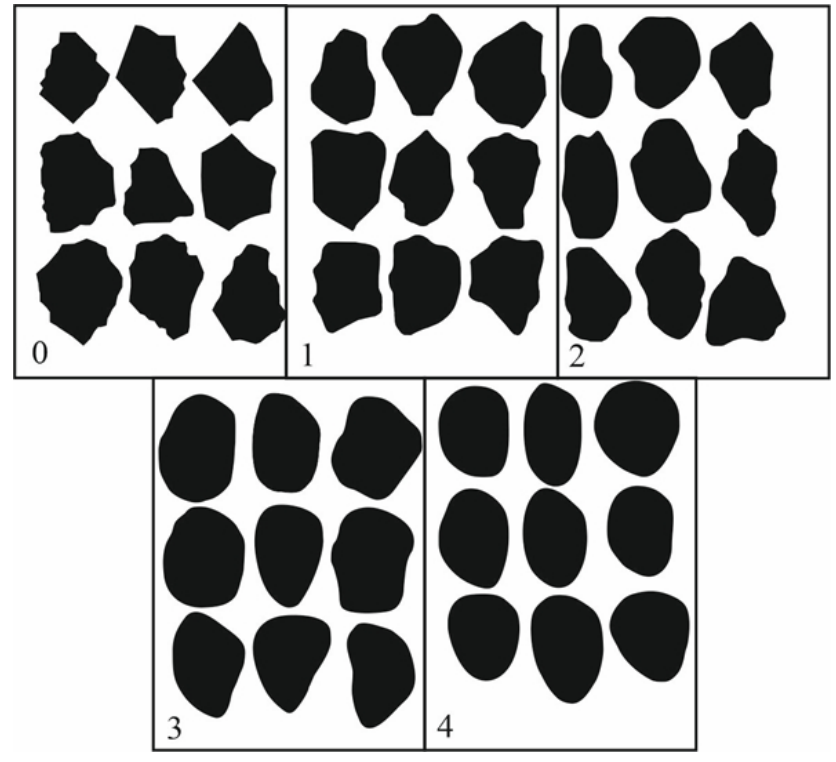

Figure 2. Patterns (Rukhin, 1969) 0 - 0, 1 - I, 2 - II, 3 - III, and 4 - IV are the classes of roundness (Khabakov, 1946).

ined sand quartz grain micromorphology covered peat histic sand deposits in the area of the Siberian Uvals, the valleys of the rivers Taz and Pur (Velichko et al., 2011), and aeolian sediments of the southern part of Western Siberia (e.g. Sizikova and Zykina, 2015).

The potassium-feldspar-based infrared optically stimulated luminescence (IR-OSL) dating method was applied to produce an absolute chronology of the deposits from the five sections studied in the present work. The upper limit of the method is normally $300-500 \mathrm{ka}$, depending on burial conditions and the physical properties of the mineral. The reliability of the dating technique used in the present 
Table 2. Remotely sensed features of glacial and fluvioglacial relief.

\begin{tabular}{ll}
\hline Relief features & Remotely sensed features \\
\hline Kame-like & $\begin{array}{l}\text { Irregularly scattered hills and ridges with their relative elevation not exceeding 10-20 m (Fig. 2). The hills have a } \\
\text { plateau-like summit; the slopes are gently convex; the gradient of the slope varies. The hills and ridges are easily } \\
\text { identified on the DSM against the flattened background; often they are separated by no-outflow basins and hollows. } \\
\text { The hills are at the highest parts of the watersheds and often from groups or even curved chains oriented NE to SW } \\
\text { or E to W. Sparse vegetation areas are associated with the highest parts of the hills. }\end{array}$ \\
\hline End moraines & $\begin{array}{l}\text { Mostly associated with the watersheds. They are narrow, tortuous upheavals (relative elevation is up to 5-7 m, some- } \\
\text { times to 10 m). The survival rate varies. They can be in the form of high linear upheavals with steep slopes to a chain } \\
\text { of low hills 10-12 km long. With high-resolution DSMs (2-10 m), the small local boundary moraine formations are } \\
\text { easily identified; for mid-resolution DSMs (25-30 m) the large features with a low survival rate are identified. The } \\
\text { key properties are the length and the position: the flat moraine pattern usually forms an interconnected structure } \\
\text { that reflects the ice sheet extents and the stages of its degradation. }\end{array}$ \\
\hline $\begin{array}{l}\text { As opposed to the terminal moraine ridges, the linear ridges are smaller and shorter while their direction is more } \\
\text { pronounced (almost no bends). When ridges are poorly expressed, an additional indicator is a linear structure of } \\
\text { the multispectral image caused by the similar orientation of the river valleys, chains of small lakes, forest and bog } \\
\text { boundaries. }\end{array}$ \\
$\begin{array}{l}\text { Twisted similarly to smooth river meanders. Nowadays they are swamped and turned into lakes. Merging and split- } \\
\text { ting, they form a typical pattern of the hydrographic network. The valleys are often associated with expected drain } \\
\text { water sources mostly located in glacial accumulative formations on the watersheds. The valleys often terminate } \\
\text { with chains of lakes perfectly visible in satellite images. }\end{array}$ \\
\hline Valley trains
\end{tabular}

study is demonstrated by comparative results obtained using several numerical dating methods (mollusc-shell-based electron spin resonance (ESR), quartz-based optically stimulated afterglow (OSA), U-Th, ${ }^{14} \mathrm{C}$ ) applied to the same sedimentary samples (Molodkov, 2012). An overview of the IR-OSL dating procedure is presented by Molodkov and Bitinas (2006). All IR-OSL ages reported in this paper were obtained in the Research Laboratory for Quaternary Geochronology (RLQG), Department of Geology, Tallinn University of Technology.

In addition to the analysis at the sampling area, samples were taken for petrographic examination. The samples were cut perpendicular to the bedding direction (if any) and made into transparent sections. The Carl Zeiss AxioScope A1 optical microscope at the Geology and Mineralogy Institute, SB RAS (Novosibirsk) was used.

For the first time for the studied area, digital surface models (DSM) with a spatial resolution of 12 and $26 \mathrm{~m} / \mathrm{px}$ based on TerraSAR-X and TanDEM-X radar data were used to characterise the geomorphological structure. The mapping is based on the remote features available in the literature (Atkinson et al., 2014; Astakhov et al., 2016, etc.) and the comparison of the field and remote-sensing data (Table 2).

In addition, public multi-spectrum space images from Sentinel-2 (10 m/px.) were used to clarify the location of such natural features as rivers, lakes, swamps and forests (https://scihub.copernicus.eu/, last access: 10 April 2020).

\section{Results}

\subsection{Characteristics of the sections}

The summary results of the Quaternary sediment section study are shown in Figs. 3-7 and Appendix Tables A1 and A2. From the data obtained, the following characteristic conditions of sediment accumulation can be distinguished.

1. Alluvial deposits predominate at the lower geomorphological level (up to $40-45 \mathrm{~m}$ ). Sections K-1 and NS-6 show the similar structure of the second above-ground terrace of the Nadym and Tanlov rivers: in the upper part, thick podzolised soil is formed over the aeolian deposits, in the middle part, floodplain-type deposits dominate, and in the lower part they are replaced by wellleached grey layered sand. Down the profile, the $\mathrm{SiO}_{2}$ content increases, while the content of other chemical elements is low. The middle part of the section is dominated by fine- and medium-grained sand; the portion of large fractions increases in the lower part where single pebbles of up to $3-4 \mathrm{~cm}$ are found. There are no permafrost-affected sediments.

2. At the middle level, the sections show the structure of an NS-13/14 kamiform hill and a linearly oriented relief (NS-20). The top of the hill is covered with a solid layer of pebbles; at $1.2 \mathrm{~m}$ depth, it is followed by coarse sand. Sandy deposits forming two distinct cycles are exposed in the middle part of the hill. The unbroken red-coloured sand is followed by black sand with a slightly horizontal 

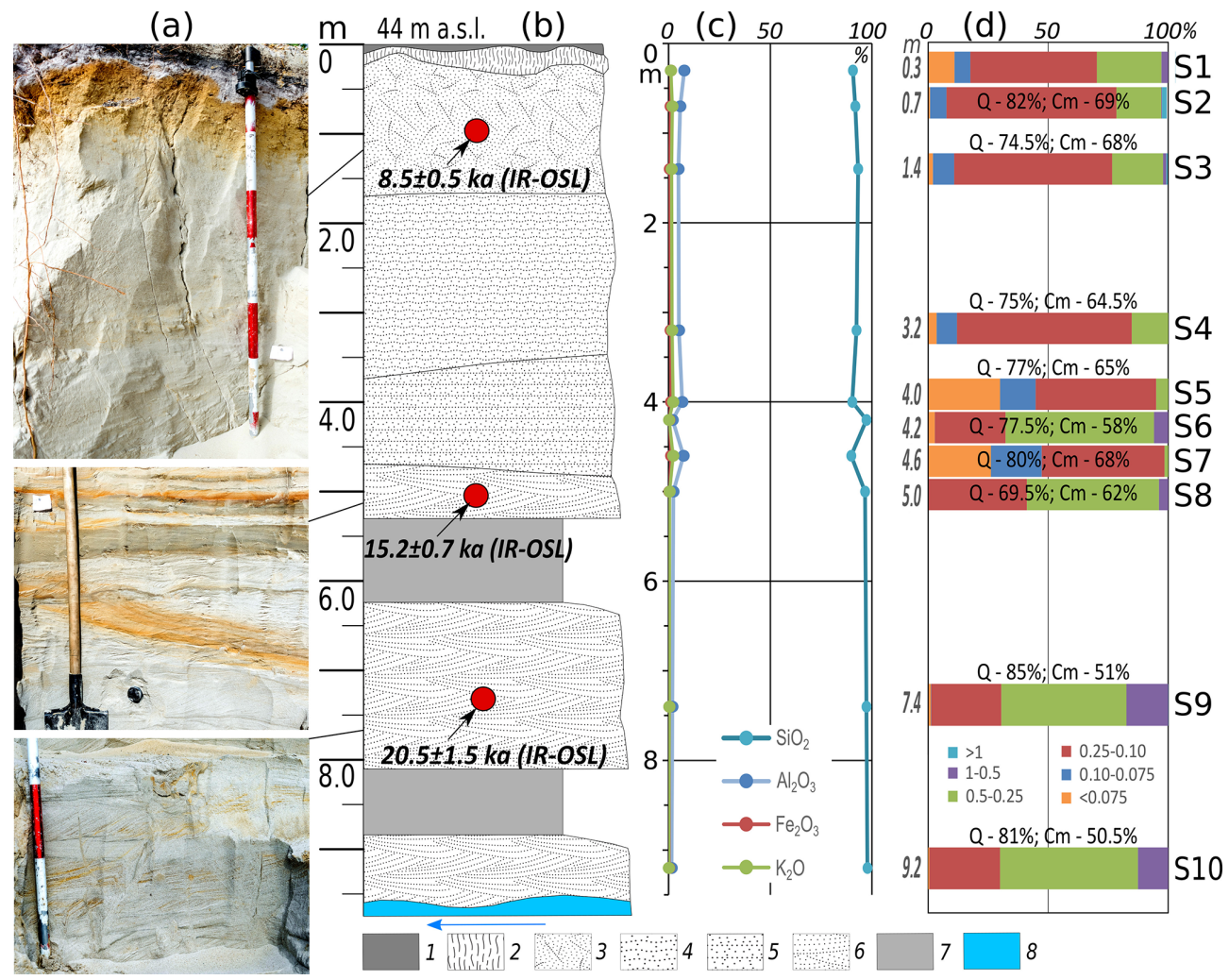

Figure 3. Summary results of research for section NS-6. (a) Photographs (by Sizov in 2017); (b) geological structure and the dating results (see Table 3); (c) bulk chemical data; (d) grain size distribution (fractions, mm). Symbols: (1) podzol horizon of modern soil; (2) illuvial-iron (spodic) horizon of modern soil; (3) sands without stratification; (4) undulating sand with secondary ferruginisation; (5) horizontally layered sand with stratification of loam; (6) medium- and coarse-grained oblique sand; (7) colluvium; (8) river level; $Q$ : coefficient of roundness of the sand quartz grains; $\mathrm{Cm}$ : degree of dullness; $\mathrm{S}$ : sample number.

orientation, which in turn is followed by light-grayish horizontally layered sand. In the lower profile, the cycle is repeated; the difference is that the layer of intensively reddish sand is not as thick. In the left lower part of the section, there is a frost wedge micro-depression, filled with the overlying layer sediments. In general, the section is dominated by medium- and coarse-grained sands of monomineral composition (the shares of $\mathrm{Fe}, \mathrm{Al}$ and other chemical elements are insignificant).

In section NS-20, the slope of the extended elevation is exposed. It is composed of a monotonic body of grey monomineral parallel and oblique-oriented quartz sand. The sands throughout the section have an identical grey colour and fine-grained composition. The presence of thin ferruginisated layers does not affect the chemical composition of sediments: $\mathrm{SiO}_{2}$ prevails in all layers. Local hills up to 5-8 $\mathrm{m}$ high covered with large pebbles and boulders on the surface were found on the top of the ridge along the survey path. In an exploration ditch on the top of the micro-hill (1.5 m deep), largegrained, non-laminated sandy sediments with an abundance of angular pebbles, gravel and single large (up to $30-40 \mathrm{~cm}$ ) boulders were exposed. Their structure is similar to the deposits of the upper part of section NS13/14. In sections, permafrost sediments preserve traces of frost cracking.

3. NS-22 is at the upper watershed in a small quarry. The quarry exposes sandy and sandy-loam bedded deposits of the large hill. Sands in the sample are grey-coloured and fine- and medium-grained. The $\mathrm{SiO}_{2}$ content is $96.49 \%$. A huge number of large, weakly rounded boulders, up to $1.5 \mathrm{~m}$ in size, was found in the quarry and on the sandbank of the nearest lake $(100-200 \mathrm{~m}$ from the quarry).

It should be noted that grey fine, medium- and coarsegrained sands of monomineral quartz composition are present in all sections (except for NS-13/14). In river terraces, such sands have oblique lamination, while on the watershed they are oriented horizontally. The sands have no permafrost features, cracking traces and, in general, poor chemical composition. A landscape vegetation feature of such sediments is sparse pine forests, which are able to grow on poor sandy soils with a welldrained hydrologic behaviour. Sandy soils lack the or- 

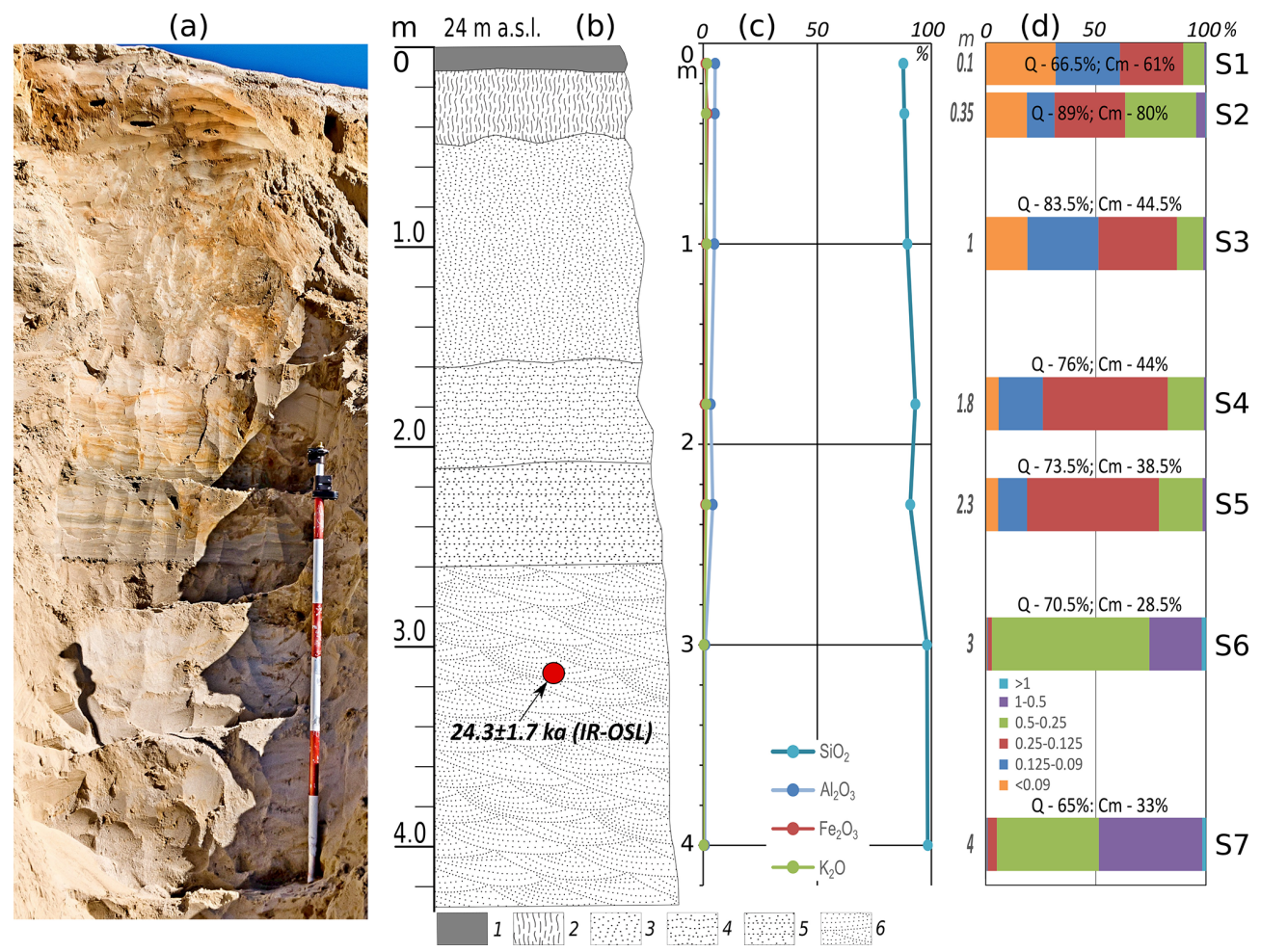

Figure 4. Summary results of research for K-1 section: (a) photograph (by Sizov in 2016); (b) geological structure and the dating results (see Table 3); (c) bulk chemical data; (d) grain size distribution (fractions, mm). Symbols: (1) podzol horizon of modern soil; (2) illuvial-iron (spodic) horizon of modern soil; (3) sands without stratification; (4) undulating sand with secondary ferruginisation; (5) horizontally layered sand with stratification of loam; (6) medium- and coarse-grained oblique sand; (7) colluvium; (8) river level; $Q$ : coefficient of roundness of the sand quartz grains; $\mathrm{Cm}$ : degree of dullness; $\mathrm{S}$ : sample number.

ganic materials and debris of fossil clams and do not show any salt content. Despite the presence of large debris on the scree slopes, boulders do not occur directly in the sands. Based on morphological, granulometric and chemical features, we infer that this type of sand sediment could be formed in subaquatic conditions in more severe environments as compared to modern climatic conditions.

\subsection{Sediment dating results}

From section K-1, a single date of $24.3 \pm 1.7$ (RLQG 2443057) was obtained at the depth of $3.2 \mathrm{~m}$. According to this age, its formation took place at the very end of the third (Lipovka-Novoselovo) warm phase, which was recorded in the north of Western Siberia during MIS 3 (Marine Isotope Stage 3) by both the ${ }^{14} \mathrm{C}$ (Kind, 1974) and mollusc-shellbased ESR (Molodkov, 2020) methods.

The normal sequence of the youngest ages of $20.5 \mathrm{ka}$ (RLQG 2565-118), 15.2 ka (RLQG 2564-118) and $8.5 \mathrm{ka}$ (RLQG 2563-019) was obtained for section NS-6 at the depths of 7.3, 5.0 and $1.0 \mathrm{~m}$, respectively. Specific analytical features suggest the supply of the sedimentary rock from the same source area. The genesis of the deposits is also identi- cal. It implies similar conditions for the rock transfer despite the likely difference in climatic conditions.

Somewhat unexpected were the dating results for two consecutive layers in section NS-13/14: $427.0 \mathrm{ka}$ (RLQG 2568019 ) and $373.0 \mathrm{ka}$ (RLQG 2567-019). Finding very old Pleistocene deposits (MIS 11) is exceedingly rare. Judging from the analytics, the sedimentary rock in these layers came from different source areas and has fluvial, most likely river, genesis. Under the given conditions of burial and physical properties of the mineral, the upper dating limit may be at least 3 times higher (i.e. up to about $1 \mathrm{Ma}$ ).

The last two datings at $123.3 \mathrm{ka}$ (RLQG 2578-059) and $112.2 \mathrm{ka}$ (RLQG 2577-059) were obtained from two sections: NS-22 and NS-20, respectively. Their common feature is that both of them fall into MIS 5, as well as the fact that the corresponding sedimentary rock also came from various source areas. The studied sediments on the base of a group of key features are supposed to have fluvial (river and lake) origin.

\subsection{Sand quartz grain morphoscopy and morphometry}

Refer to Appendix Figs. A1-A10 for the key results: coefficient of roundness, degrees of dullness and examples of the 
(a)

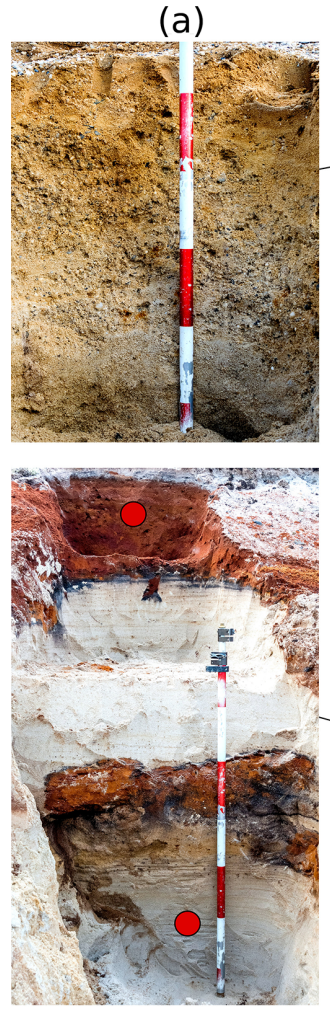

(b)

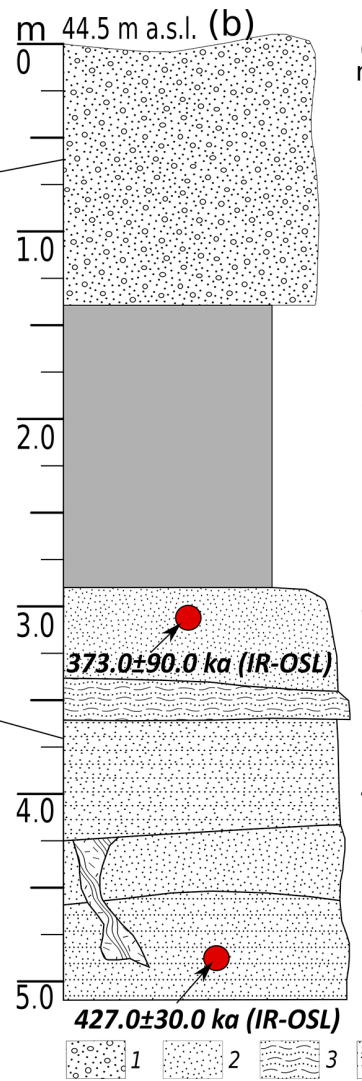

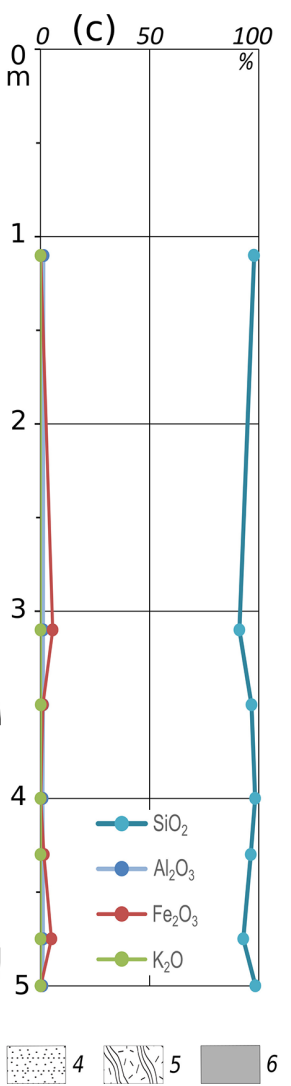
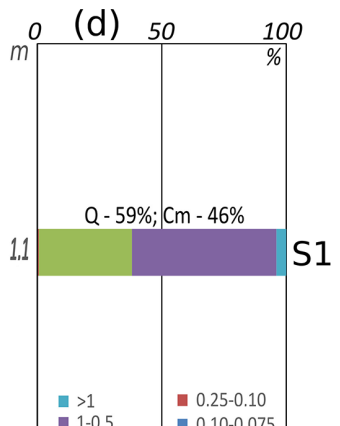

\begin{tabular}{l|l}
$1-0.5$ & $=0.10-0.075$ \\
0.0 .25 & $=0.075$
\end{tabular} $=0.075$

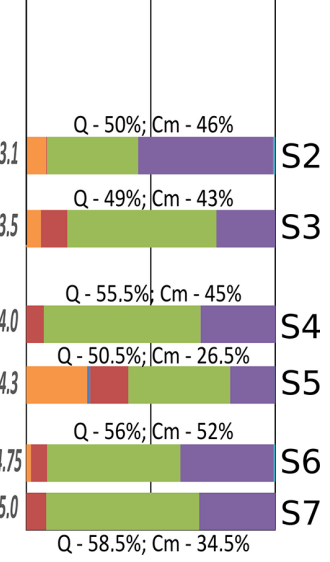

\section{1}

Figure 5. Summary results of research for NS-13/14 section: (a) photographs (by Sizov in 2017); (b) geological structure and the dating results (see Table 32); (c) bulk chemical data; (d) grain size distribution (fractions, mm). Symbols: (1) coarse sand with pebbles; (2) unstratified red sand; (3) undulating black sand; (4) horizontally layered sand; (5) wedge filled by deposits of the overlying layer; (6) colluviums; $Q$ : coefficient of roundness of the sand quartz grain; $\mathrm{Cm}$ : degree of dullness; $\mathrm{S}$ : sample number.

Table 3. IR-OSL ages and the related analytical data for the sediment samples from the sites studied.

\begin{tabular}{lrrrrrr}
\hline \multicolumn{7}{c}{ Absolute dating by the IR-OSL method } \\
\hline Section & Sampling depth & Sample code & Age & U (ppm) & Th (ppm) & K (\%) \\
\hline K & 3.15 & RLQG 2443-057 & $24.3 \pm 1.7$ & 0.11 & 0.45 & 0.01 \\
NS-6 & 1.0 & RLQG 2563-019 & $8.5 \pm 0.5$ & 0.79 & 0.73 & 0.94 \\
NS-6 & 5.0 & RLQG 2564-118 & $15.2 \pm 0.7$ & 0.01 & 0.00 & 0.14 \\
NS-6 & 7.3 & RLQG 2565-118 & $20.5 \pm 1.5$ & 0.01 & 0.00 & 0.14 \\
NS-13/14 & 3.1 & RLQG 2567-019 & $373.0 \pm 90.0$ & 0.00 & 0.00 & 0.00 \\
NS-13/14 & 4.9 & RLQG 2568-019 & $427.0 \pm 30.0$ & 0.35 & 0.74 & 0.00 \\
NS-20 & 1.1 & RLQG 2577-059 & $112.2 \pm 8.3$ & 0.96 & 4.19 & 0.34 \\
NS-22 & 1.0 & RLQG 2578-059 & $123.3 \pm 9.4$ & 1.29 & 2.00 & 1.31 \\
\hline
\end{tabular}

quartz grain appearance. The following is a brief description of the main features.

$N S-6$. This is the Aeolian genetic group. The upper part of the section (samples $\mathrm{S} 2$ and $\mathrm{S} 3$ ) is characterised by a high coefficient of roundness (Q; 74.5\%-82\%) and degree of matting (Cm; 68\%-69\%). Matte grains from rounding class IV prevail; the complete grain distribution vs. rounding and surface dullness are shown in Appendix Fig. A1. The most com- mon element of the grain microrelief in the $\mathrm{S} 1$ sample is a micro-pitted surface (Appendix Fig. A6a, b), which is a feature of aeolian transportation (Velichko and Timireva, 1995). Chemical etching is sometimes found in depressions. High coefficients of roundness $(Q)$ and degrees of dullness $(\mathrm{Cm})$ along with the predominance of micro-pitted grain texture suggest the dominance of aeolian processes during the sedimentation. Several grains show signs of subaquatic treatment 


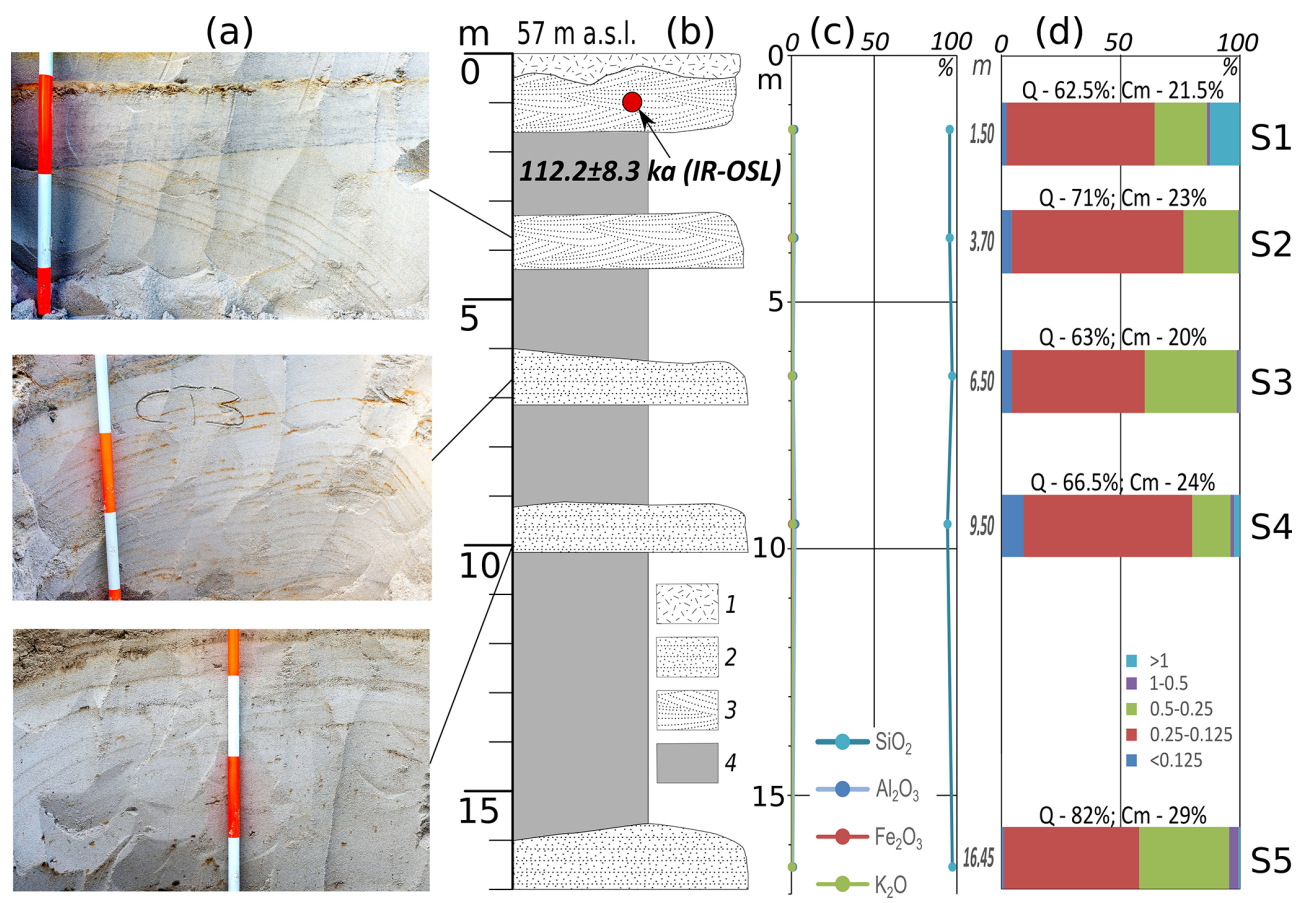

Figure 6. Summary results of research for section NS-20: (a) photographs (by Sizov in 2018); (b) geological structure and the dating results (see Table 3); (c) bulk chemical data; (d) grain size distribution (fractions, mm). Symbols: (1) overburden; (2) horizontally layered sand; (3) medium- and coarse-grained oblique sand; (4) colluvium; $Q$ : coefficient of roundness of the sand quartz grains; Cm: degree of dullness; S: sample number.

and origin in the form of crescentic depressions and V-shaped percussions (Appendix Fig. A6a, b), which preceded the aeolian stage. This seems to be associated with the accumulation of rock from the river valleys.

For quartz grains from the floodplain deposits (samples S4-S8), the rounding coefficient $(Q)$ is within the range of $65 \%-80 \%$; the degree of dullness $(\mathrm{Cm})$ is $58 \%-68 \%$ (Fig. 3). On average, rounding class IV grains (refer to Appendix Fig. A1) with a half-matte surface prevail in the samples. The number of completely glossy grains increases (up to $22 \%$ ). The entire grain surfaces have signs of subaquatic processing: V-shaped percussions (Appendix Fig. A6d), often forming a fine-pitted surface (Appendix Fig. A6c, d), and separate crescent gouges. Many grains show traces of aeolian treatment, expressed as a micro-pitted texture (Appendix Fig. A6c), which corresponds well to a sufficiently large share of matte grains in the sample. It can be assumed that deposits of this layer are formed by fluvial river and aeolian processes in the coastal environment.

For samples from the lower part of the section (samples $\mathrm{S} 9$, S10) $Q=81 \%-85 \%$ and $\mathrm{Cm}$ is $50.5 \%-51 \%$. Most grains belong to the rounding class IV. The number of glossy grains (up to $32 \%$ ) is significantly higher than in overlying sediments (Appendix Fig. A1). The primary grain treatment traces on the surface of all grains, regardless of the roundness and dullness, are fine-pitted surfaces (Appendix Fig. A6e, f) and individual well-developed $\mathrm{V}$-shaped micro-depressions

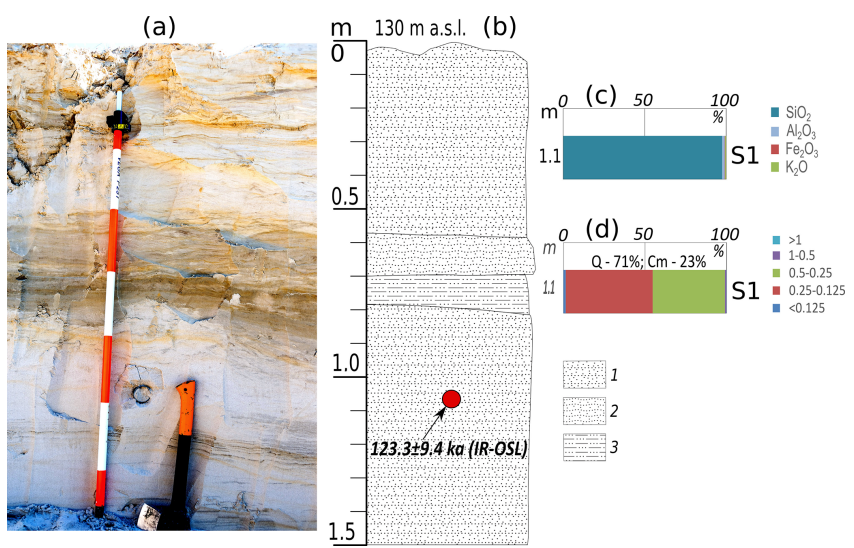

Figure 7. Summary results of research for section NS-22: (a) photographs (by Sizov in 2018); (b) geological structure and the dating results (see Table 3); (c) bulk chemical data; (d) grain size distribution (fractions, mm). Symbols: (1) horizontally layered grey sand; (2) oblique layered sand; (3) horizontally layered sandy loam; $Q$ : coefficient of roundness of the sand quartz grain; $\mathrm{Cm}$ : degree of dullness; S: sample number.

(Appendix Fig. A6f), which are a sign of active river fluvial transportation. There are grains of roundness classes II and III; they differ from most grains by the presence of flat faces (Appendix Fig. A6g, h). The shapes of these grains resulted from the previous stages of grain treatment. 
There are also signs of aqua treatment on their surfaces (Appendix Fig. A6g, h).

$K-1$. Grain distribution across the section matches the morphometric and morphological properties of the NS-6 section well. Refer to Appendix Fig. A2 for the grain distribution by roundness and dullness. Layer 6 (samples S6-S7) lying at the base of the section provides important information. These samples differ in grain morphology from overlying sediments. They are characterised by the lowest cross-sectional values of the coefficient of roundness $(63 \%-65 \%)$ and the degree of matting (33\%-35\%), the presence of glossy grains in all classes of roundness (Appendix Fig. A6), constrained or ground flat faces at grains, and the development of a sickle-like texture and fine pits on the grain surface. With these features, it can be concluded that this layer was formed by fluvial processes, but it should be emphasised that there is a rock in its composition that may have been exposed to glacial processes in the past.

For $\mathrm{S} 1$ deposits $Q=59 \%$ and $\mathrm{Cm}=46 \%$. Angular grains, class I (32\%) and medium-rounded grains, class II (24\%) predominate. Most grains have half-matte (34\%) and quarter-matte (32\%) surface (Appendix Fig. A3). The grains can be categorised into two groups. The first group is represented by well-rounded mature grains with a ubiquitous fine-pitted surface (Appendix Fig. A8a), which is a sign of treatment by aqueous streams. In the second group, there are grains of irregular shape (Appendix Fig. A8b), often with multiple or conchoidal fractures. The faces have traces of treatment in a subaquatic environment. Grains of the second group show separate V-shaped and rarely crescent-shaped percussions; their number and location indicate a lower exposure to water flow. The presence of these two different groups of grains suggests the ingress of rock from different sources of the rock. One of them could be the sub-angular fluvioglacial deposits.

For underlying deposits (S2-S7) $Q=49 \%-58.5 \%$ and $\mathrm{Cm}=26.5 \%-52 \%$. There, poorly rounded and mediumrounded grains of classes I and II with a glossy or quartermatte surface prevail (Appendix Fig. A3). The grain surface is dominated by traces of low-activity subaquatic treatment: V-shaped and crescentic micro-depressions (Appendix Fig. A8c-h). Irregular grains with smooth surfaces are most common, often with fractures (Appendix Fig. A8e, $\mathrm{f}, \mathrm{h}$ ), which probably indicates their arrival from a source with poorly rounded materials. There are grains with conchoidal fractures formed by desquamation processes due to grain freezing (Velichko and Timireva, 1995) or under a great pressure applied to the grain (Immonen et al., 2014; Vos et al., 2014). There are also V-shaped percussions along their surface, suggesting that the deformation occurred before the last fluvial treatment. Many grains were highly exposed to chemical processes expressed as etching through the depressions on the grain and the $\mathrm{Fe}-\mathrm{Mn}$ skins. The development of $\mathrm{V}$-shaped forms only along the protruding parts of the grain, a well-developed crescent-shaped texture and non-ubiquitous fine pits, the average values of the coefficient of roundness, and low degrees of maturation suggest that the final processing of grains occurred in a relatively calm aquatic environment. For S2 and S3 samples, in addition to traces of subaquatic treatment, there are grains with small micro-pits (Appendix Fig. A8c, d), a sign of aeolian treatment of grains.

$N S$-20. For samples S1-S5, the coefficient of roundness $(Q)$ is in the range of $62.5 \%-82 \%$ and the degree of dullness $(\mathrm{Cm})$ is $20 \%-29 \%$. Glossy grains of II and III classes of roundness prevail (Appendix Fig. A4). In most sediments (S1), there are signs of aeolian treatment of grains expressed as micro-pits (Appendix Fig. A9a, b). However, they have a rather low value of $\mathrm{Cm}$, which is not typical of aeolian deposits. This suggests that the local aeolian redeposition of underlying sediments occurred. The underlying layers (S2-S5) have sediment features; their formation is probably associated with fluvioglacial processes: the surface of most grains is highly uneven, cavernous and strongly mechanically deformed. These properties can be found in glacial conditions (at the stages of previous processing). This is also suggested by the presence of deep pits, grooves and parallel scratches of various configurations (Appendix Fig. A9c, d, h). The last agent in their treatment was a subaquatic process, as indicated by frequently occurring V-shaped and crescentic depressions (Appendix Fig. A9e, f, g).

$N S$-22. The coefficient of roundness $(Q)$ is $79 \%$ and the degree of dullness $(\mathrm{Cm})$ is $31 \%$. Most of the grains belong to class III of roundness; a slightly smaller number of grains are of class IV; glossy grains prevail (Appendix Fig. A5). The morphology of the grain surface is quite uniform and is mainly represented by grains with fine pits covering the grain surface almost completely (Appendix Fig. A10a-f) or developed only on micro-elevation parts of the grain (Appendix Fig. A10e, f). This surface is a characteristic feature of long-term grain processing in a sufficiently active subaquatic environment.

\subsection{Petrography}

The petrographic analysis of 15 samples taken in a quarry nearby the section AS-3 (Fig. 8; coordinates: $65.061417^{\circ} \mathrm{N}$, $72.943848^{\circ} \mathrm{E}$ ) enabled us to distinguish between several groups of materials.

1. The first group (six samples) is presented by grey, yellowish-grey and greenish-grey fine-grained and very fine-grained sandstone and siltstone with slab jointing. These are usually moderately or poorly sorted and have primary foliation that is emphasised by the regular orientation of flattened grains, varying grain size and matrix content. The matrix is hydro-micaceous clay, sometimes with ferruginous cement, with a small portion of silica. The fragments are usually sub-rounded or sub-angular. The rock is composed of polymictic sandstones, similar to arkose sandstones. Quartz and feldspar prevail among the mineral grains, composing 
$\sim 30 \%$ by volume of the fragments, while another third is predominantly composed of siliceous rock fragments. Some samples contain significant amounts of muscovite (up to $5 \%$ by volume), chlorite (including pseudomorphs after the dark-coloured minerals) and epidote. The presence of muscovite could be an indicator of low weathering of initial sediments.

2. Pebbles and boulders of the second group of quartzitic and quartz sandstone (six samples) feature angular forms. The textures are usually massive and vary from poorly to well sorted. The cement is predominantly quartz or quartz-hydro-micaceous, sometimes with goethite. The grain size varies greatly, but mediumsized varieties prevail. More than $95 \%$ of grains are quartz and siliceous lithoclasts, while muscovite, feldspar, epidote, zircon, monazite and opaque minerals are also present. The quartzitic sandstones show regenerative incrustations around the primary rounded quartz grains. The grain boundaries are most often irregular and frequently saw-shaped, which indicates a notable meta-genetic alternation. Late veins of the fine-grained quartz aggregate are also rather frequent.

3. The third group of samples was the least numerous yet the most informative. In this case, the first sample is a cobble of pinkish quartz trachyte-alkaline intermediate volcanic rock. Large pelletised phenocrysts of potassic feldspar (up to $1 \mathrm{~cm}$ ) and rare fine quartz grains are distributed in the groundmass composed of pelletised potassic feldspar and quartz (Fig. 8a). Furthermore, quartz-feldspathic myrmekites are rather frequent. There are small quantities of plagioclase, darkcoloured minerals that are substituted by aggregates of chlorite, epidote and opaque mineral.

The second sample is dolerite with a typical poikilitic texture (Fig. 8b) formed by large poikilite clinopyroxene crystals (3-4 $\mathrm{mm}$ in diameter) with tabular plagioclase (up to $1-1.5 \mathrm{~mm}$ ). There are large, separate subhedral grains of basaltic hornblende (up to $2 \mathrm{~mm}$ ), which are substituted by hydrous ferric oxides, titanite and chlorite. The main groundmass contains plagioclase and significant amounts of chlorite, which is presumably a product of substitution of the volcanic glass or clinopyroxene microliths.

The third sample is zoisite-amphibolite (zoisite-actinolite) metasomatic rock. Light-green idiomorphic grains of amphibole prevail over hypodiomorphic crystals and sheaf-like aggregates of zoisite. Anhedral segregations of titanite and opaque ore minerals are also present. From a general chemical perspective, it can be suggested that the most probable protolith for this rock was a dolerite-like rock.

\subsection{Geomorphological analysis}

The investigated area is in the zone of sparse northern taiga with extensive peatlands. Therefore, the existing DSM, based
Table 4. Remote mapping of the glacial and fluvioglacial relief features in the Nadym River basin (mid and lower courses).

\begin{tabular}{lrr}
\hline Relief features & $\begin{array}{r}\text { Number of } \\
\text { identified } \\
\text { objects }\end{array}$ & $\begin{array}{r}\text { Total } \\
\text { area/length } \\
(\mathrm{km})\end{array}$ \\
\hline Kame-like hummocks & 157 & - \\
End moraines & 122 & 851.3 \\
Parallel ridges & 16 & 157.2 \\
Valley trains & 103 & 1411.3 \\
\hline
\end{tabular}

on X-band radar data with high penetration capacity, reflects in detail the terrain structure of the territory. DSM mapping of the glacial ice and fluvioglacial relief features was performed using a site with an area of $54117 \mathrm{~km}^{2}$ as an example. Its boundaries run along the watershed of the Nadym River and its tributaries. The summary mapping results are shown in Fig. 9 and Table 4.

Based on the map obtained (Fig. 9), it can be noted that the spread of the assumed glacial and fluvioglacial relief features within the investigated area has two distinct patterns.

- All identified features are to the south off the Yarudey and Right Khetta rivers, with individual objects found in the watershed between Yarudey and Heigiyahi (Longjugan). In the southern and western parts, the diversity and density of the features are the highest (Tanlova and Right Khetta rivers watershed, left bank of the Nadym River in its middle course).

- All identified features are found at heights of $40 \mathrm{~m}$ a.s.l. and higher; the density of objects significantly increases in the watershed areas above $70-75 \mathrm{~m}$.

The feature of the high-elevation relief distribution is demonstrated by the statistical data about the selected kamelike hummocks. Among the 157 point objects, 145 (92\%) are above $75 \mathrm{~m}$, with $53(34 \%)$ located within the narrow range of 95-104 m. Below $75 \mathrm{~m}$, large objects occur individually and are poorly distinguished morphologically.

The network of extended (more than $850 \mathrm{~km}$ ) proximal (kame) moraines that mark the final glacial massif positions is confidently recognised. They have different stretches (sublatitudinal, north-western, etc.), which may indicate there was no single direction of the cover ice movement. In most cases, the moraines are confined to the watersheds, while they are often accompanied by other glacial forms (kames, valley trains, etc). The chain of kame hills on the watershed of the Tanlova and Right Khetta rivers is an erosive remnant of the local moraine formations; i.e. morphologically they occupy an intermediate position between the individual moraines. On the watersheds, well-drained dry areas of sands near kame ridges are often subjected to deflation and active redispersal. 
(a)

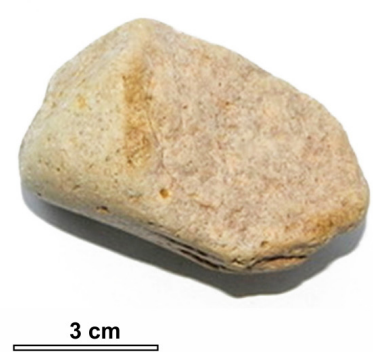

(b)

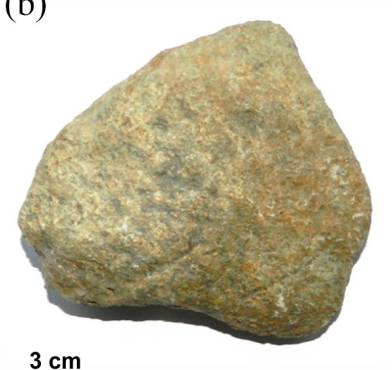

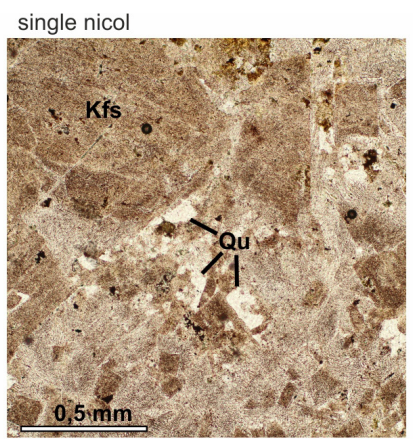
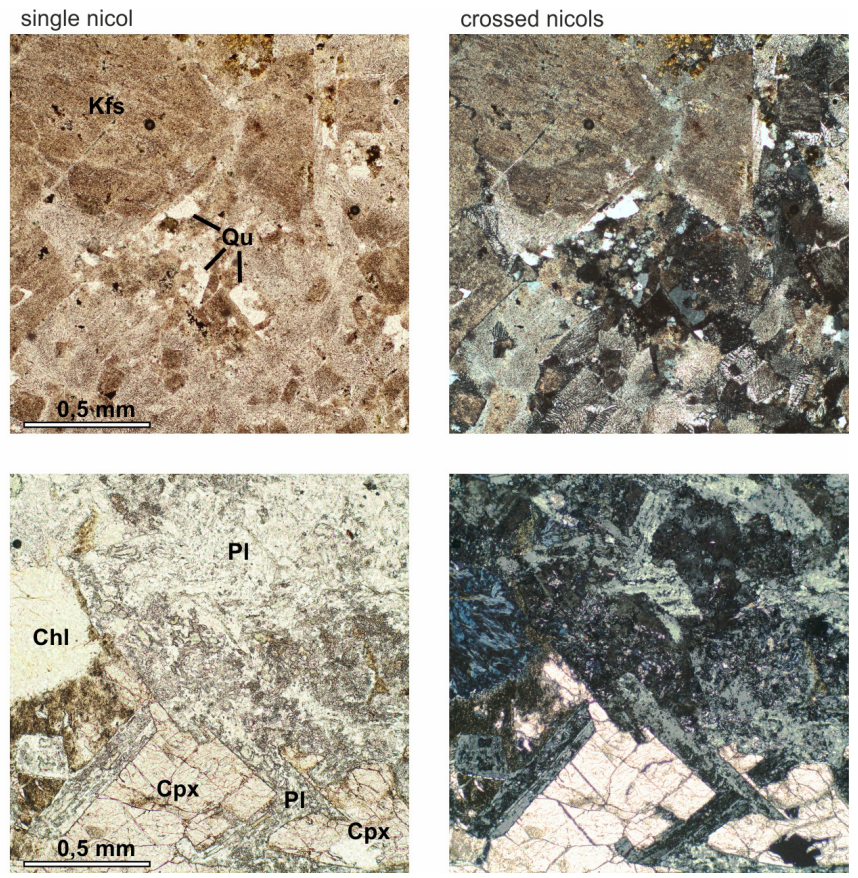

Figure 8. (a) Sample N-10 - pinkish quartz trachyte, with large inclusions of potassic feldspar (Kfs) with fine quartz grains (Qu) in the quartz-feldspathic matrix; (b) sample N-14: greenish-brown dolerite, with large poikilitic clinopyroxene crystals (Cpx) with thin plagioclase crystals $(\mathrm{Pl})$; in the groundmass: plagioclase chlorite $(\mathrm{Chl})$.

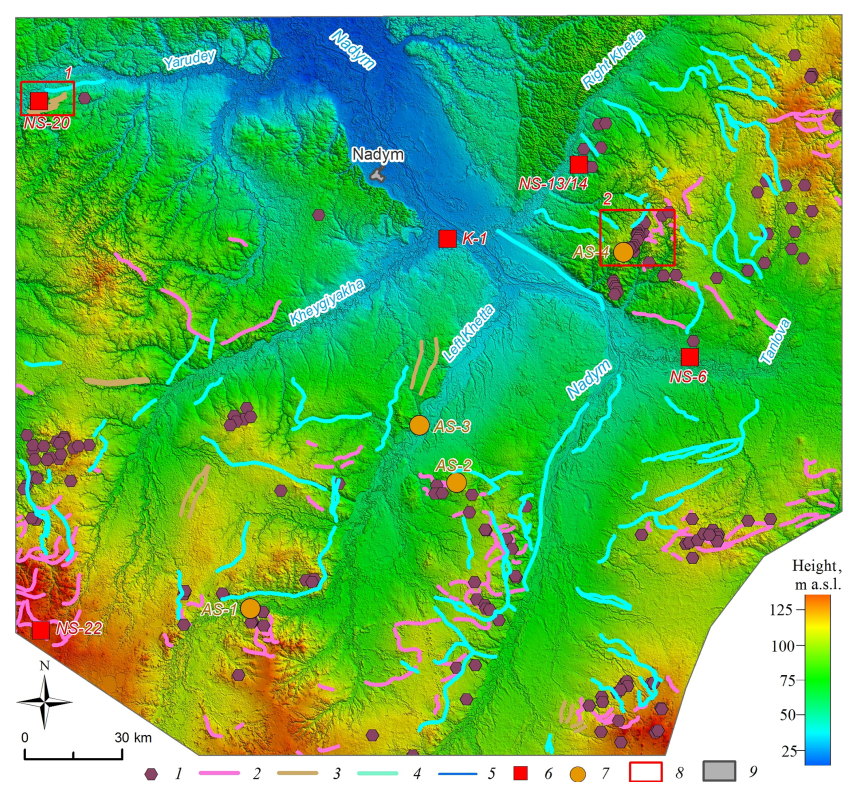

Figure 9. Results of the glacial and fluvioglacial relief interpretation in the middle course of the Nadym River (the background image is based on TanDEM-X DEM (C DLR, $26 \mathrm{~m} / \mathrm{px}$ ): (1) kame-like hummocks; (2) moraines; (3) parallel ridges; (4) valley trains; (5) waterways; (6) studied and sampled locations; (7) additional locations based on Khlebnikov (1954) and Yevseyev and Reynin (1958); (8) areas of typically glacial landforms; (9) settlements (objects 1-4,6,7 are available in GIS-format at Sizov, 2020).
Some of the individual objects are linear ridges (about $157 \mathrm{~km}$ total length). The linear ridge relief also has visible signs of erosion (scours, rills, subsidences) and in most cases can be traced as a specific linear landscape texture.

The valleys and rills of the melt glacial water flow are more than $1400 \mathrm{~km}$ long. The valleys are well expressed in the southern and eastern parts of the study area and are barely visible below $40 \mathrm{~m}$ a.s.l. The network of valleys does not really match the modern watercourses; they can be located both in parallel at a small distance from the ancient valleys or intersect them at right angles. The valleys and hollows of the ancient runoff are often associated with terminal formations. The preservation of valleys is one of the key signs of marine transgression absent in the middle course of the Nadym River since the last glaciation of the region.

For clarity, two sections of typically glacial landforms are highlighted on the map (Fig. 9).

1. A site with a predominant linear ridge relief, located on the right bank of the Yarudey River (left tributary of the Nadym River), near the Nadym-Salekhard highway under construction (Fig. 10): four long, curved ridges reaching a height of $55 \mathrm{~m}$ are well-preserved (the difference in relative heights is $10-12 \mathrm{~m}$ ); to the south of the ridges stands a section of hilly, presumably kame, relief; the ridges are complicated by thermokarst and erosion features. 


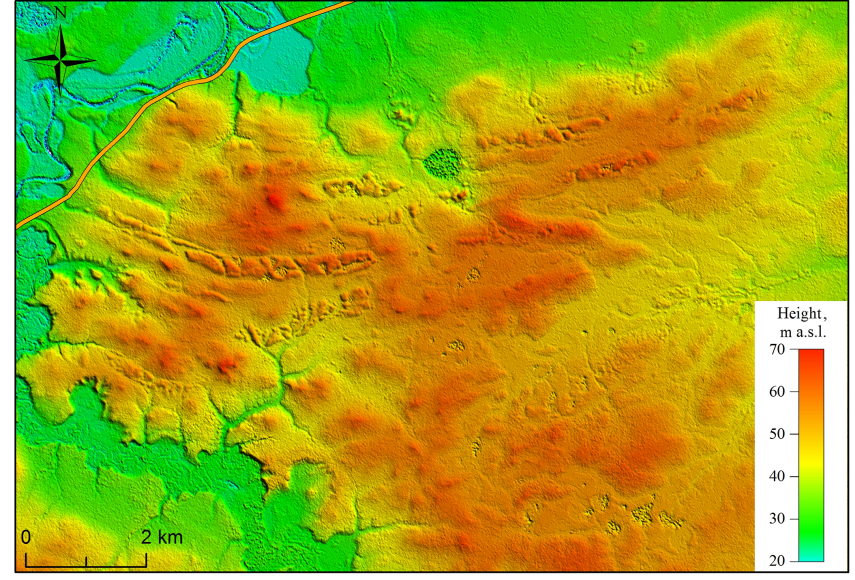

N Nadym-Salekhard highway

Figure 10. Parallel ridges, TanDEM-X DEM @ DLR, 12 m/px

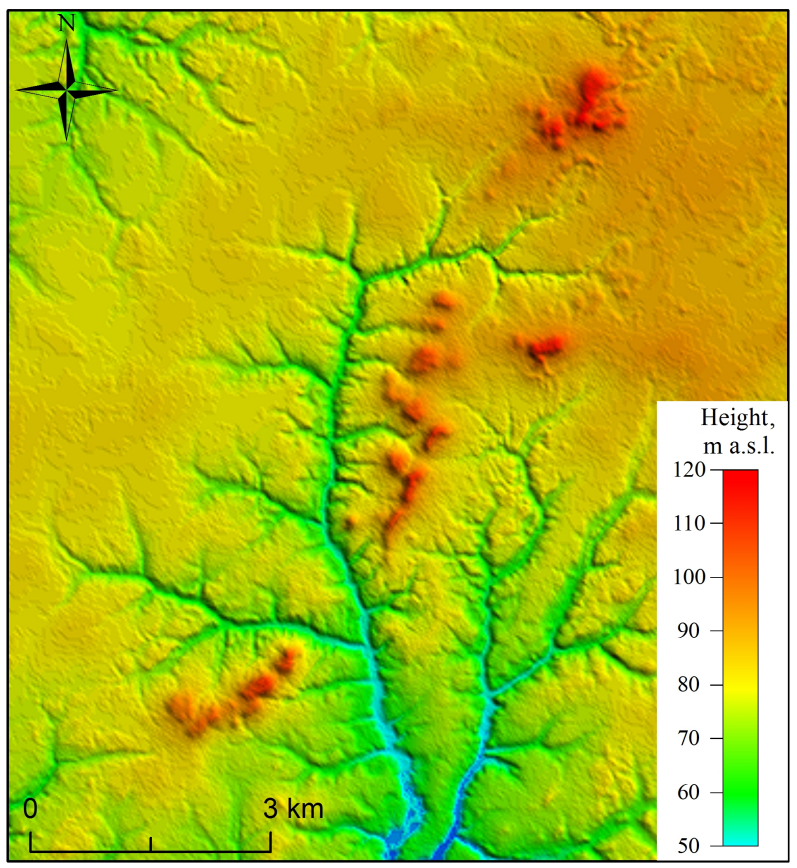

Figure 11. Kame-like features, TanDEM-X DEM $\odot$ DLR, 26 m/px.

2. The kame hill concentration site on the right bank of the Nadym River (Fig. 11); the kames reach an absolute height of more than $100 \mathrm{~m}$ (difference in relative height up to $30 \mathrm{~m}$ ); the kames are well-preserved despite the destruction of individual features by the river erosion.

\section{Discussion}

According to current viewpoints, the territory of the north of Western Siberia was exposed to several cover glaciations: Zyryanka (MIS 4), Taz (MIS 6) and Samarovo (MIS 8). Areas at the lower level (up to 40-45 $\mathrm{m}$ a.s.l.) could represent

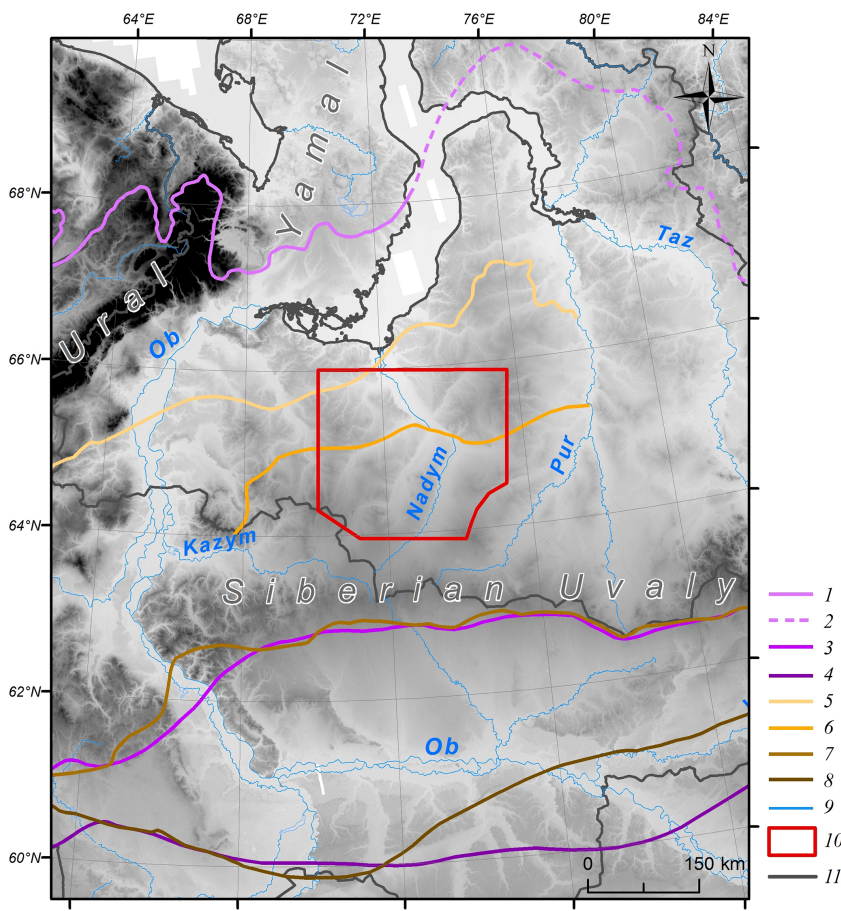

Figure 12. (1-8) Ice sheet boundaries: (1) Zyryanka (Astakhov et al., 2016); (2) Zyryanka (assumed) (Astakhov et al., 2016); (3) Taz (Astakhov et al., 2016); (4) Samarovo (maximum) (Astakhov et al., 2016); (5) Zyryanka (Zemtsov, 1976; Babushkin, 1996); (6) Taz (second stage) (Zemtsov, 1976; Babushkin, 1996); (7) Taz (Zemtsov, 1976); (8) Samarovo (Zemtsov, 1976); (9) water bodies; (10) study area; (11) administrative boundaries. Background: TanDEM-X $90 \mathrm{~m}$ DEM $\odot$ DLR.

serial repeated marine transgressions in Kazantsev (MIS 5) and Karga (MIS 3) time periods in Fig. 13. Directly within the boundaries of the investigated areas the boundaries of Taz (MIS 6) and possibly Zyryanka glaciation periods are identified (Zemtsov, 1976; Babushkin, 1996).

The key natural feature of the glacial genesis of Quaternary strata in northern Western Siberia is the presence of wrecked rock: semi-rounded angular stones, gravel and large boulders with evident glacial striation, carried over by the glacier from the territories outside the Western Siberian Plain (Strelkov et al., 1965; Zemtsov, 1976). The waterglacial sediments in the research area include well-washed grey sand characterised by poor chemical composition (the gravimetric concentration of $\mathrm{SiO}_{2}$ is $94 \%-97 \%$ ) and also containing amendments of gravel and stones (Chekunova, 1954; Groysman, 1954; Khlebnikov, 1954). The glacial sediments include unsorted coarse-grained sands with an abundance of pebbles, as well as moraine-like bodies of lumped clay, loam and clay sand with gravel and large boulders. The petrographic composition of boulders and pebbles includes quartz, opal, sandstones, quartz porphyries, amphibolites, granitoids, gneisses and trachytes (Chekunova, 1954; Groysman, 1954; Khlebnikov, 1954). However, it was noted 


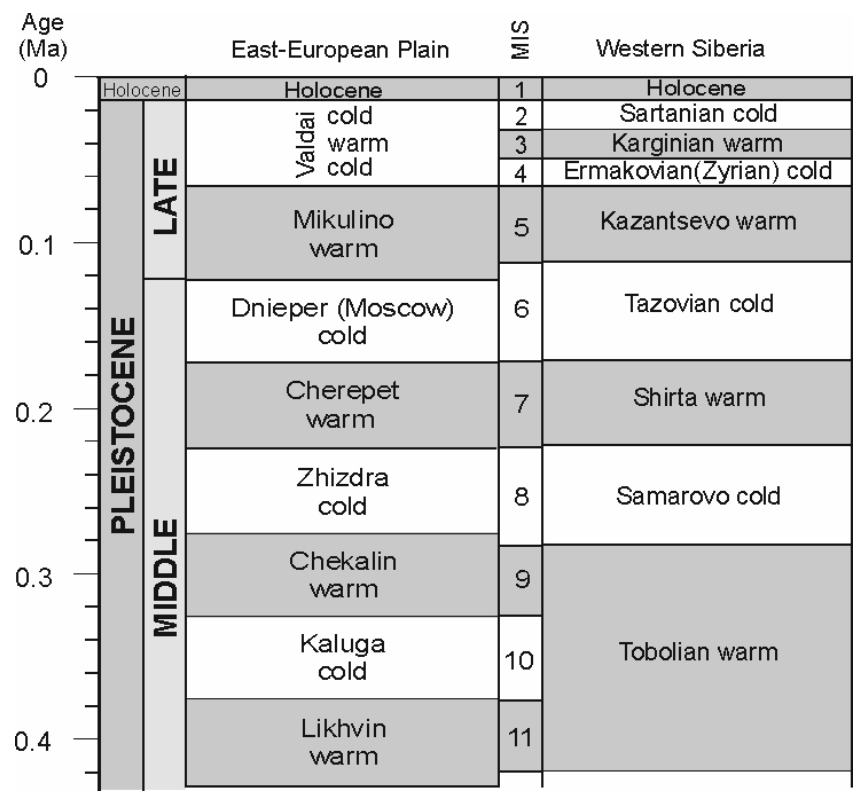

Figure 13. Palaeoenvironmental event successions on the East European Plain (from Bolikhovskaya, 2004; Molodkov and Bolikhovskaya, 2010) and in Western Siberia (Zhamoida, 2015).

that interpreting the exact location of the origin of these rocks from the geological markers representing different territories is so far problematic.

The results of the study of the sections, in general, showed that the youngest of the discussed sediments are those of the second floodplain terrace (section NS-6, K-1). In the top part, this includes aeolian sand formed no later than the beginning of the Holocene (MIS 1); in the middle part there are floodplain series of alluvium; in the lower part there are river streams of grey oblique sand of the late MIS 3-middle MIS 2.

The absolute age of the second floodplain terrace formation of the Nadym and Tanlova rivers (sections K-1 and NS-6) correlates well with radiocarbon and OSL datings of postglacial Pleistocene sediments throughout all of northern Western Siberia (the age ranging from 42000 to 25000 years) (Astakhov and Nazarov, 2010). On average, the age of the cover formation is between 20000 and 12000 years (Astakhov, 2006; Zemtsov, 1976). Two types of glacial relief areas and extensive sandur surfaces were identified on the surface of the second floodplain terrace in the large-scale field studies on the left bank of the Left Kheta River (Vasilyev, 2007).

At the middle and upper geomorphological level, grey monomineral sand with a similar age to the beginning of the NS-20 stage was also found in the NS-22 and both sections MIS 5 in age. It can be suggested that during the Kazantsev interglacial period in the vast area of the Nadym River basin there were favourable conditions for the erosion of the previously accumulated sandy textured deposits and their transfer downstream the main rivers.
One of the most interesting points of research is the kameform hill on the left bank of the Right Khetta River (NS13/14); the formation of its middle part corresponds to the Tobol interglacial period (MIS 9-11). It can be suggested that the sediments in the upper part of the hill are not younger than the Taz glaciation (MIS 6), while the pebble layer formed during the degradation of the glacier reinforced the previous sediments and later was resistant to erosion and was not covered by the waters of the Kazantsev and Karga transgressions

The results of the sand quartz grain morphology analysis confirmed the supposed genesis of the studied sections. Thus, for sections NS-6 and K it was shown that in the upper part of sections the sequence is aeolian sediments, alluvial flood plain facies and channel facies of coarse stratified sands. At the base of both sections, there are sediments in which, apart from typical river grains, a large number of grains of various morphologies are found. These are grains of varying degree of roundness and irregular shape, with a smooth surface and smooth faces; often on their surface, there are various grooves and scratches formed under a strong mechanical impact, as well as conchoidal fractures. Their origin could be the result of freezing weathering and cryogenic transformation (Velichko and Timireva, 1995), as well as of high pressure applied to the grain surface (Immonen et al., 2014; Vos et al., 2014). Well-rounded ellipsoid and ball-shaped grains predominate in the top layer sediments. One can associate this distribution with materials coming from two different sources. One source could have been the former glacial sediments eroded by fluvial processes. This type of terrace structure corresponds well with the results of the study by Velichko et al. (2011), who analysed sands with underlay peat deposits in the investigated region.

Quartz grains from sections NS-13/14 and NS-20 are often characterised by low rounding classes, multiple conchoidal fractures, sometimes even conchoidal systems, a deep-pitted surface, scratches, grooves and cleavage surfaces. Such elements could be signs of processes that occur in glacial environments. Often, there are also signs of subsequent water treatment: separate crescentic depressions and smoothed sharp peaks of grains. It indicates the redeposition of the glacial grains by water flows. Along with the grains described above, there are also typical subaquatic grains, i.e. well-rounded with a fine-pitted surface, but their number is inferior to grains with glacial features.

Currently, we lack sufficient evidence to confirm the glacial genesis of these deposits. It is possible that the grains were exposed to the effects of glacial processes, with a final processing phase in their history that included subaquatic processes. In section NS-22, the grain morphology provides evidence that suggests the existence of a quiet subaquatic environment under which quartz grains underwent long-term treatment.

In general, the results of sand quartz grain morphoscopy and morphometry show that most quartz grains from all sec- 
tions underwent complex multi-stage processing throughout their life.

The petrographic diversity of erratic boulders in Western Siberia helps us distinguish between two or three paleo-glacial regions that combine several dozen distributed provinces. Each is characterised by a specific set of rocks and petrographic features. The first major generalisation in this respect was made by Zemtsov (1976), who identified the guide boulders of the Ural region as ultramafic and mafic rocks of the main (axial) Uralian zone, plagio-granites, and highly metamorphosed rocks (gneisses and shales). In the central Siberian region, the prevailing boulders include dolerites and basalts of the Putorana Plateau, as well as various granitoids, quartzites and Palaeozoic sandstones of the Taimyr Region. These studies were substantially supplemented in detailed work by Sukhorukova et al. (1987).

Despite their small quantity, the petrographic analysis of pebbles and boulders led to the following conclusions. First, high-silica alkaline effusive rocks (sample N-10, quartz trachyte) are indicative of both the northern Taimyr Province (Troitsky and Shumilova, 1974) and many moraines of the Ural paleo-glacial region (Sukhorukova et al., 1987), but they are never found in the Putorana Plateau and the southernmost regions. Moreover, there is only a small relative share of dolerites (sample N-14, dolerite) and other effusive mafic rocks, which is a property of the Putorana and Nizhnyaya Tunguska regions. In contrast, there is no limestone that would be typical of the central Siberian paleo-glacial region (Kulyumbinsk and Sukhaya Tunguska distributive provinces according to Sukhorukova et al., 1987). There is no granite in the samples either, which is a property of the northern Taimyr region.

Second, quartz and quartzite sandstones are typical for the Ural paleo-glacial region, but their share is usually within a few per cent. Quartzitic sandstones also described as Palaeozoic were found $50 \mathrm{~km}$ north of Surgut within the tentative central Siberian and middle rock outwash zones (Sukhorukova et al., 1987). The source of the polymictic platy jointing sandstone could be the Palaeozoic bordering of the eastern slope of the Urals (Sukhorukova et al., 1987) or the Mesozoic sandstone of the Western Siberian Plate.

In general, the samples have a significant proportion of terrigenous rocks (sandstones and siltstones) and low content of dolerites. On the one hand, this can be explained by the poor representativeness of the samples. Nevertheless, the key washout zone could be located further north than the Putorana Plateau in the Taimyr area. To substantiate this point of view, further research is planned to determine the trace element composition and absolute dating and to expand the sampling.

Despite the numerous features that make it possible to attribute the thickness of grey monomineral quartz sand (K-1, NS-6, NS-20) to fluvioglacial sediments and the upper pebble strata of section NS-13/14 to glacial sediments, the study did not find typical moraine-like formations of lumped clay, loam and clay sand with gravel and large boulders in this territory. However, detailed descriptions of this type of sediment can be found in some references (Strelkov et al., 1965; Zemtsov, 1976; Sukhorukova et al., 1987; Babushkin, 1996).

Thus, in the middle course of the Left Khetta River at Point 70 (Khlebnikov, 1954) at $2.5 \mathrm{~m}$ deep there is a $20 \mathrm{~m}$ thick unit of densely clumped loam with interlayers of mica-enriched sand (the layers are up to $25 \mathrm{~cm}$ thick) (section AS-1, Fig. 9). The colour of the loam is brown, small glitter mica is visible, and angular debris (granite) is found, up to $25 \mathrm{~cm}$ in diameter. In the right part of the section upstream, stripping exposed a layer of fine-grained sand. Below $15 \mathrm{~m}$ it is followed by an interlayer of gravel-pebble rock. The prominent colluvium slope is covered by loam-crushed stone, and a cluster of gravel-pebble rock is also found on the towpath.

The huge moraine was described in the watershed of Nadym and Left Khetta rivers (point 2368) (section AS-2, Fig. 9) (Khlebnikov, 1954). It has a wide extension and rises up to $25-30 \mathrm{~m}$ above the surrounding plain. The ridge part of the range is convex and consists of individual peaks separated by meso-ridges. On the surface of the ridge, the congestion of pebble and gravel is found. The gravel-pebble, coarsegrained, well-washed and leached sand is traced down to the depth of $1.2 \mathrm{~m}$.

Two esker-like linear elevations and a small kameform hill were discovered in the lower course of the Right Khetta River at well no. 18 (Khlebnikov, 1954) at $1.8 \mathrm{~m}$ depth in the gravel-pebble horizon with a total depth of $17.6 \mathrm{~m}$ (section AS-3, Fig. 9). The diameters of the pebbles are between 0.5 and $3-4 \mathrm{~cm}$. The pebbles are not rounded and consist mainly of quartz and sandstone.

The moraine hills in the upper part of the Bolshoy Huhu River (right tributary of the Nadym River) have a north-west and a north-east orientation. The length reaches $6-7 \mathrm{~km}$, and the relative height varies from 15 to $60 \mathrm{~m}$ (Yevseyev and Reynin, 1958). Morphologically, the steep slopes of the hills have individual smoothed tops separated by small saddles. The upper layer of the hills to a depth of $1-2 \mathrm{~m}$ is peeled loam with abundant pebble rock. The pebbles are weak and poorly rounded, and their diameters do not exceed $2-4 \mathrm{~cm}$. Petrographic composition in one of the sections reveals (socalled point 367, Chekunova, 1954) silica, clay shale, arkose sandstones, breccia of clay-quartz rocks and limonite. The results of manual drilling at some small hills (Yevseyev and Reynin, 1958; Andreev, 1960) showed that they are folded with permafrost sediments. The total ice content as determined visually is not less than $30 \%$. As an example, well no. 10 (Yevseyev and Reynin, 1958), where light grey clay with a yellowish colour, which is light and porous, with aleurite interlayers, is found at a depth of $1.4-10.7 \mathrm{~m}$; it has a wavy and horizontal lamination (section AS-4, Fig. 9). Clay thickness is underlaid with grey clay and fine-grained sands with poor sorting and admixture of gravel grains, quartz and silicon pebbles.

Data from both our studies and previous field ones are in good correspondence to the results of the analyses with the 
Tandem-X digital terrain models. These models revealed that despite the plain origin of the territory and the high salinity and dominance of erosion processes, various glacial and fluvioglacial relief features preserved to various degrees (kameform hills, proximal moraines, linear elevations, glacial meltwaters, etc.) are evident.

A linearly oriented relief caused by a glacial impact in northern Western Siberia is highlighted on the Map of Quaternary Formations in Russia (1:2500000 scale; Astakhov et al., 2016). At the same time, linear features and glacial remains are identified on geological maps of larger scales (Babushkin, 1995).

Nowadays, due to the increasing availability of digital elevation models, remote mapping of glacial relief features has become the standard method across the world (Clark et al., 2004; Glasser et al., 2008; Sharpe et al., 2010; Fredin et al., 2012; Atkinson et al., 2014; Norris et al., 2017). Based on modern spatial data, a detailed map for the "British Isles territory and coastal zone" (BRITICE-2) is available for digital study and analysis and was updated (Clark et al., 2018). The remote features of most forms of glacial relief for various natural conditions are described in detail and offer numerous pieces of evidence that can be used as standards for remotesensing data interpretation, including the entire northern area of Western Siberia.

\section{Conclusions}

Our results showed a high efficiency of the simultaneous application of field ground and remote methods even with limited raw site rocks. Sediments were identified which can be immediately attributed to fluvioglacial (lower part of section K-1 and NS-6, section NS-20) and glacial (upper layer of section NS-13/14) origins. Traces of glacial treatment were also found as landforms in certain areas such as kameform hills, proximal moraines, linear-bed elevations and depressions of melt glacial water runoffs. Due to low organic substance content and sparse lichen, pine trees are formed over the fluvioglacial sediments on the low-fertility podzolic soils. It is a characteristic landscape feature of the leaching soil condition for the north taiga in Western Siberia. At the same time, the moraine-like layers of aggregated clay, loam and clay sand with gravel and large stone boulders that could not be found in field studies are widely described in sources previously unpublished (particularly the Left Khetta and the upper reaches of the Great Huhu River).

Thus, the development history of the Nadym River lower stream area provides evidence that periods of cover glaciations occurred here in the Pleistocene. At the same time, it is difficult to say whether it was a single glacier with a common front or whether there were several separate centres of ice accumulation. The available data, especially the structure and functional characteristics of the relief, appear to favour the second option, at least in the Late Pleistocene. In the early periods, traces of larger glaciation may represent the vast lake alluvial plains and flood plains, reaching a maximum area in the basin of the Nadym, Pur and Taz rivers. In this case, they can be regarded as the latest erosion formations but have preserved a characteristic structure inherited by modern landscapes. 


\section{Appendix A}

Table A1. Bulk content of chemical elements.

\begin{tabular}{|c|c|c|c|c|c|c|c|c|c|}
\hline \multirow{2}{*}{$\begin{array}{l}\text { Sampling } \\
\text { depth (m) }\end{array}$} & \multirow[t]{2}{*}{ Sample no. } & \multicolumn{8}{|c|}{ Bulk content $(\%)$} \\
\hline & & $\mathrm{SiO}_{2}$ & $\mathrm{Al}_{2} \mathrm{O}_{3}$ & $\mathrm{Fe}_{2} \mathrm{O}_{3}$ & $\mathrm{~K}_{2} \mathrm{O}$ & $\mathrm{Na}_{2} \mathrm{O}$ & $\mathrm{P}_{2} \mathrm{O}_{5}$ & $\mathrm{CaO}$ & $\mathrm{TiO}_{2}$ \\
\hline \multicolumn{10}{|l|}{$\mathrm{K}-1$} \\
\hline 0.1 & $\mathrm{~S} 1$ & 87.65 & 5.27 & 0.95 & 1.66 & 1.00 & 0.03 & 0.51 & 0.64 \\
\hline 0.35 & $\mathrm{~S} 2$ & 88.09 & 5.14 & 1.89 & 1.14 & 0.56 & 0.05 & 0.32 & 0.53 \\
\hline 1 & S3 & 89.49 & 4.93 & 1.20 & 1.52 & 0.75 & 0.04 & 0.41 & 0.41 \\
\hline 1.8 & S4 & 92.97 & 3.35 & 0.61 & 1.32 & 0.51 & 0.02 & 0.27 & 0.21 \\
\hline 2.3 & S5 & 90.71 & 4.21 & 0.92 & 1.35 & 0.64 & 0.03 & 0.38 & 0.39 \\
\hline 3 & S6 & 98.02 & 0.88 & 0.30 & 0.25 & 0.07 & 0.01 & 0.10 & 0.10 \\
\hline 4 & S7 & 98.39 & 0.69 & 0.25 & 0.20 & $<0.05$ & 0.01 & 0.08 & 0.08 \\
\hline \multicolumn{10}{|l|}{ NS-6 } \\
\hline 0.3 & $\mathrm{~S} 1$ & 90.60 & 6.20 & 0.87 & 0.91 & 0.63 & 0.08 & 0.28 & 0.37 \\
\hline 0.7 & $\mathrm{~S} 2$ & 91.85 & 4.57 & 0.74 & 1.47 & 0.58 & 0.01 & 0.41 & 0.37 \\
\hline 1.4 & S3 & 93.22 & 3.92 & 0.51 & 1.15 & 0.57 & 0.01 & 0.31 & 0.25 \\
\hline 3.2 & S4 & 92.37 & 4.05 & 0.75 & 1.38 & 0.62 & 0.02 & 0.43 & 0.35 \\
\hline 4 & S5 & 90.32 & 5.39 & 0.98 & 1.74 & 0.62 & 0.02 & 0.46 & 0.47 \\
\hline 4.2 & S6 & 97.33 & 1.54 & 0.26 & 0.15 & 0.45 & 0.00 & 0.18 & 0.08 \\
\hline 4.6 & S7 & 89.79 & 5.86 & 0.95 & 1.80 & 0.65 & 0.03 & 0.63 & 0.35 \\
\hline 5 & S8 & 96.65 & 1.88 & 0.28 & 0.42 & 0.49 & 0.01 & 0.20 & 0.11 \\
\hline 7.4 & S9 & 97.29 & 1.46 & 0.24 & 0.25 & 0.48 & 0.01 & 0.16 & 0.07 \\
\hline 9.2 & $\mathrm{~S} 10$ & 97.78 & 1.19 & 0.21 & 0.07 & 0.45 & 0.01 & 0.17 & 0.07 \\
\hline \multicolumn{10}{|l|}{ NS-13/14 } \\
\hline 1.1 & $\mathrm{~S} 1$ & 97.72 & 1.43 & 0.21 & 0.00 & 0.43 & 0.00 & 0.14 & 0.10 \\
\hline 3.1 & $\mathrm{~S} 2$ & 91.00 & 1.26 & 5.62 & 0.00 & 0.63 & 1.28 & 0.16 & 0.07 \\
\hline 3.5 & S3 & 96.58 & 1.22 & 1.14 & 0.15 & 0.56 & 0.12 & 0.18 & 0.11 \\
\hline 4 & $\mathrm{~S} 4$ & 98.14 & 0.99 & 0.15 & 0.00 & 0.48 & 0.00 & 0.15 & 0.07 \\
\hline 4.3 & S5 & 96.25 & 1.18 & 1.58 & 0.07 & 0.47 & 0.06 & 0.16 & 0.24 \\
\hline 4.75 & S6 & 92.75 & 1.23 & 5.08 & 0.01 & 0.64 & 0.02 & 0.18 & 0.12 \\
\hline 5 & S7 & 98.34 & 0.89 & 0.17 & 0.00 & 0.43 & 0.00 & 0.13 & 0.09 \\
\hline \multicolumn{10}{|l|}{ NS-20 } \\
\hline 1.5 & $\mathrm{~S} 1$ & 95.61 & 1.79 & 0.39 & 0.48 & 0.08 & 0.02 & 0.08 & 0.44 \\
\hline 3.7 & $\mathrm{~S} 2$ & 95.59 & 1.83 & 0.21 & 0.68 & 0.09 & 0.01 & 0.07 & 0.16 \\
\hline 6.5 & S3 & 97.12 & 1.14 & 0.19 & 0.39 & 0.09 & 0.01 & 0.07 & 0.10 \\
\hline 9.5 & $\mathrm{~S} 4$ & 94.30 & 2.31 & 0.31 & 0.84 & 0.10 & 0.02 & 0.07 & 0.38 \\
\hline 16.45 & S5 & 97.26 & 0.93 & 0.22 & 0.22 & 0.05 & 0.01 & 0.07 & 0.20 \\
\hline \multicolumn{10}{|l|}{ NS-22 } \\
\hline 1.1 & $\mathrm{~S} 1$ & 96.49 & 1.53 & 0.32 & 0.61 & 0.17 & 0.01 & 0.11 & 0.17 \\
\hline
\end{tabular}


Table A2. Spearman's coefficients of correlation.

\begin{tabular}{lrrrrrrrrrrr}
\hline & $\mathrm{SiO}_{2}$ & $\mathrm{TiO}_{2}$ & $\mathrm{Al}_{2} \mathrm{O}_{3}$ & $\mathrm{Fe}_{2} \mathrm{O}_{3}$ & $\mathrm{MnO}$ & $\mathrm{MgO}$ & $\mathrm{CaO}$ & $\mathrm{Na}_{2} \mathrm{O}$ & $\mathrm{K}_{2} \mathrm{O}$ & $\mathrm{P}_{2} \mathrm{O}_{5}$ & $\mathrm{BaO}$ \\
\hline $\mathrm{SiO}_{2}$ & 1 & -1 & -1 & -0.89 & -0.84 & -0.76 & -0.89 & -0.89 & -0.79 & -0.81 & -0.62 \\
$\mathrm{TiO}_{2}$ & -1 & 1 & 1 & 0.89 & 0.94 & 0.75 & 0.89 & 0.89 & 0.79 & 0.83 & 0.73 \\
$\mathrm{Al}_{2} \mathrm{O}_{3}$ & -1 & 1 & 1 & 0.89 & 0.94 & 0.78 & 0.89 & 0.89 & 0.79 & 0.84 & 0.73 \\
$\mathrm{Fe}_{2} \mathrm{O}_{3}$ & -0.89 & 0.89 & 0.89 & 1 & 0.93 & 0.95 & 0.75 & 0.75 & 0.61 & 0.97 & 0.61 \\
$\mathrm{MnO}$ & -0.84 & 0.94 & 0.94 & 0.93 & 1 & 0.86 & 0.85 & 0.85 & 0.76 & 0.91 & 0.78 \\
$\mathrm{MgO}$ & -0.76 & 0.78 & 0.78 & 0.95 & 0.86 & 1 & 0.67 & 0.67 & 0.52 & 0.99 & 0.54 \\
$\mathrm{CaO}$ & -0.89 & 0.89 & 0.89 & 0.75 & 0.85 & 0.67 & 1 & 1 & 0.96 & 0.71 & 0.91 \\
$\mathrm{Na} 2 \mathrm{O}$ & -0.89 & 0.89 & 0.89 & 0.75 & 0.85 & 0.67 & 1 & 1 & 0.96 & 0.71 & 0.91 \\
$\mathrm{~K}_{2} \mathrm{O}$ & -0.79 & 0.79 & 0.79 & 0.61 & 0.76 & 0.52 & 0.96 & 0.96 & 1 & 0.56 & 0.96 \\
$\mathrm{P}_{2} \mathrm{O}_{5}$ & -0.81 & 0.83 & 0.84 & 0.97 & 0.91 & 0.99 & 0.71 & 0.71 & 0.56 & 1 & 0.59 \\
$\mathrm{BaO}$ & -0.62 & 0.73 & 0.73 & 0.61 & 0.78 & 0.54 & 0.91 & 0.91 & 0.96 & 0.59 & 1 \\
\hline
\end{tabular}

Significance level $p<0.05$.

Table A3. Grain size distribution.

\begin{tabular}{|c|c|c|c|c|c|c|c|}
\hline \multirow{2}{*}{$\begin{array}{l}\text { Sampling } \\
\text { depth (m) }\end{array}$} & \multirow[t]{2}{*}{ Sample no. } & \multicolumn{6}{|c|}{ Fraction size $(\mathrm{mm}) /$ content $(\%)$} \\
\hline & & $\begin{array}{r}\text { Silt and } \\
\text { clay }\end{array}$ & $\begin{array}{r}\text { Very fine } \\
\text { sand }\end{array}$ & $\begin{array}{l}\text { Fine } \\
\text { sand }\end{array}$ & $\begin{array}{r}\text { Medium- } \\
\text { grained } \\
\text { sand }\end{array}$ & $\begin{array}{r}\text { Coarse } \\
\text { Sand }\end{array}$ & $\begin{array}{r}\text { Very } \\
\text { coarse } \\
\text { sand }\end{array}$ \\
\hline \multicolumn{2}{|c|}{$\mathrm{K}-1$} & $<0.09$ & $0.125-0.09$ & $0.25-0.125$ & $0.5-0.25$ & $1-0.5$ & $>1$ \\
\hline 0.1 & $\mathrm{~S} 1$ & 31.7 & 29.2 & 28.7 & 9.5 & 0.7 & 0.1 \\
\hline 0.35 & $\mathrm{~S} 2$ & 18.7 & 12.5 & 32.1 & 32.2 & 4.2 & 0.3 \\
\hline 1 & S3 & 18.9 & 32.3 & 35.6 & 11.9 & 1.2 & 0.1 \\
\hline 1.8 & S4 & 5.9 & 20.1 & 56.7 & 16.4 & 0.9 & 0.0 \\
\hline 2.3 & S5 & 5.6 & 13.1 & 59.9 & 19.8 & 1.6 & 0.0 \\
\hline 3 & S6 & 0.6 & 0.4 & 1.8 & 71.5 & 23.7 & 1.9 \\
\hline 4 & S7 & 0.4 & 0.5 & 4.2 & 46.3 & 46.9 & 1.7 \\
\hline \multicolumn{2}{|c|}{ NS-6 } & $<0.075$ & $0.10-0.075$ & $0.25-0.10$ & $0.5-0.25$ & $1-0.5$ & $>1$ \\
\hline 0.3 & S1 & 11.0 & 6.6 & 52.7 & 26.9 & 2.8 & 0.0 \\
\hline 0.7 & S2 & 0.8 & 6.8 & 70.8 & 18.7 & 0.4 & 1.9 \\
\hline 1.4 & S3 & 2.0 & 8.8 & 65.8 & 21.2 & 1.3 & 0.5 \\
\hline 3.2 & S4 & 3.6 & 8.4 & 72.8 & 15.2 & 0.0 & 0.0 \\
\hline 4 & S5 & 29.9 & 14.9 & 50.2 & 5.1 & 0.0 & 0.0 \\
\hline 4.2 & S6 & 2.8 & 0.0 & 29.4 & 61.9 & 5.9 & 0.0 \\
\hline 4.6 & S7 & 26.2 & 21.1 & 51.1 & 1.6 & 0.0 & 0.0 \\
\hline 5 & S8 & 0.0 & 0.0 & 41.1 & 55.0 & 3.9 & 0.0 \\
\hline 7.4 & S9 & 1.1 & 0.1 & 29.2 & 52.1 & 17.4 & 0.0 \\
\hline 9.2 & S10 & 0.5 & 0.0 & 29.4 & 57.5 & 12.6 & 0.0 \\
\hline \multicolumn{2}{|c|}{ NS-13/14 } & $<0.075$ & $0.10-0.075$ & $0.25-0.10$ & $0.5-0.25$ & $1-0.5$ & $>1$ \\
\hline 1.1 & S1 & 0.0 & 0.0 & 0.6 & 37.4 & 58.0 & 4.0 \\
\hline 3.1 & S2 & 8.0 & 0.0 & 0.3 & 36.6 & 54.2 & 0.9 \\
\hline 3.5 & S3 & 5.9 & 0.0 & 10.6 & 59.9 & 23.6 & 0.0 \\
\hline 4 & S4 & 0.0 & 0.0 & 7.1 & 62.9 & 30.0 & 0.0 \\
\hline 4.3 & S5 & 24.4 & 1.2 & 15.3 & 40.9 & 18.0 & 0.1 \\
\hline 4.75 & S6 & 1.9 & 0.0 & 6.5 & 53.5 & 37.5 & 0.6 \\
\hline 5 & S7 & 0.0 & 0.0 & 8.0 & 61.5 & 30.6 & 0.0 \\
\hline \multicolumn{2}{|c|}{ NS-20 } & $<0.09$ & $0.125-0.09$ & $0.25-0.125$ & $0.5-0.25$ & $1-0.5$ & $>1$ \\
\hline 1.5 & $\mathrm{~S} 1$ & 0.0 & 2.2 & 62.1 & 21.9 & 1.3 & 12.5 \\
\hline 3.7 & $\mathrm{~S} 2$ & 0.0 & 4.3 & 72.0 & 23.0 & 0.5 & 0.2 \\
\hline 6.5 & S3 & 0.0 & 4.4 & 55.8 & 38.5 & 1.1 & 0.3 \\
\hline 9.5 & S4 & 0.0 & 9.3 & 70.7 & 16.0 & 1.5 & 2.4 \\
\hline 16.45 & S5 & 0.0 & 0.9 & 56.8 & 37.6 & 4.0 & 0.6 \\
\hline \multicolumn{2}{|c|}{ NS-22 } & $<0.09$ & $0.125-0.09$ & $0.25-0.125$ & $0.5-0.25$ & $1-0.5$ & $>1$ \\
\hline 1.1 & S1 & 0.0 & 1.4 & 53.3 & 44.3 & 0.9 & 0.1 \\
\hline
\end{tabular}



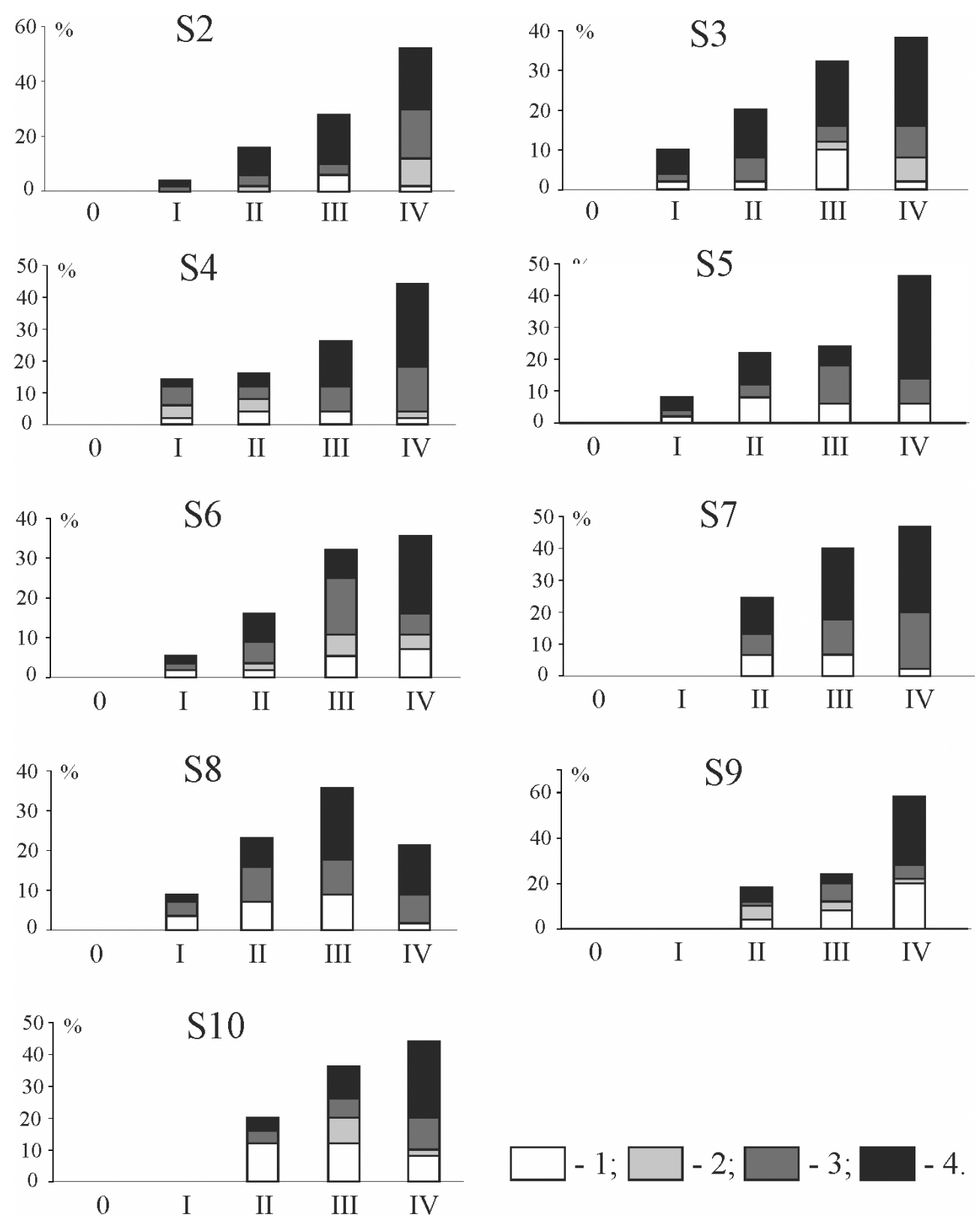

Figure A1. Distribution of quartz sand grains from section NS-6 by roundness and dullness. (1) Glossy; (2) quarter-matte; (3) half-matte; (4) matte; 0, I, II, III and IV are grades of roundness according to Khabakov (1946). 

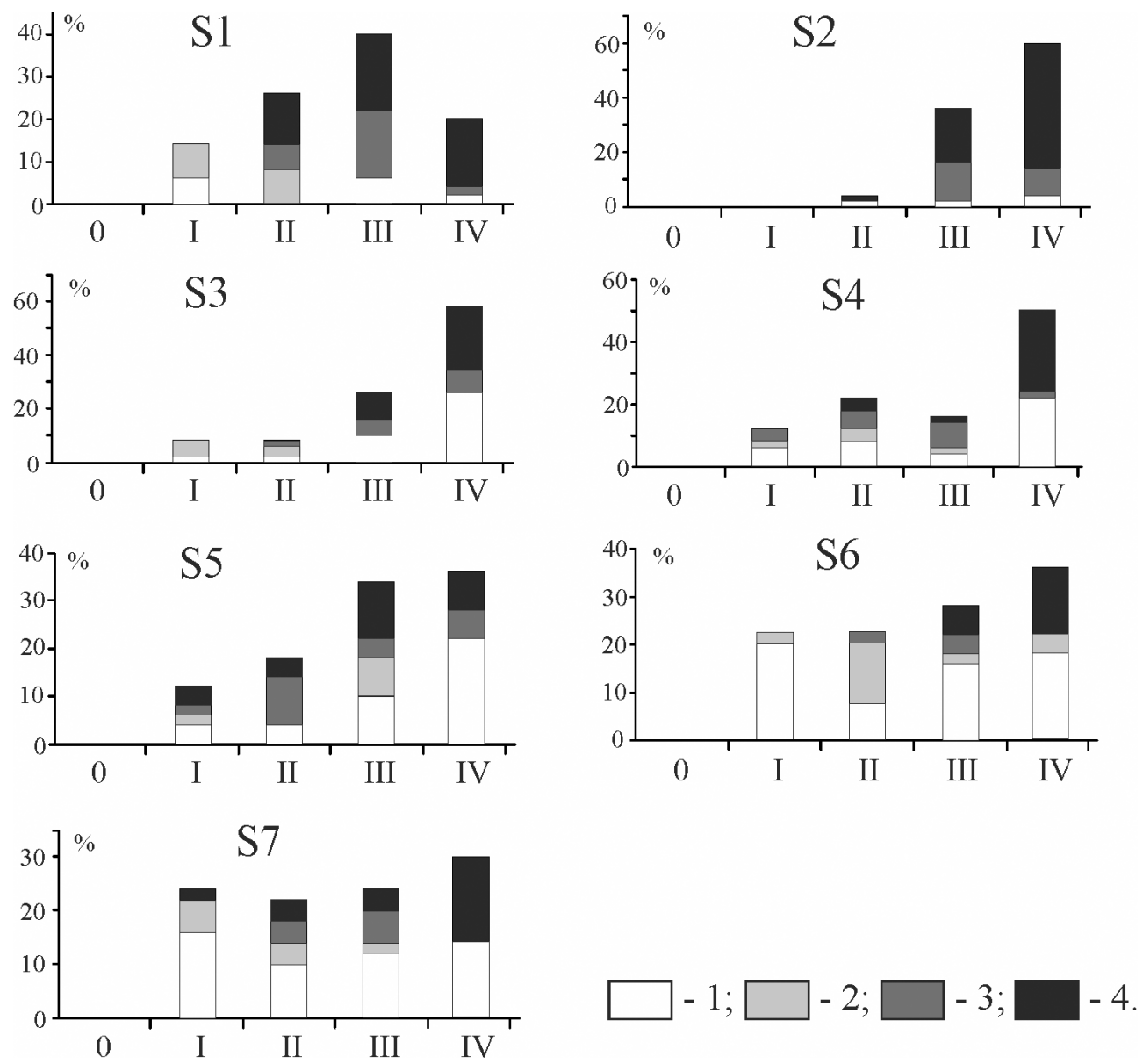

Figure A2. Distribution of quartz sand grains from section NS-6 by roundness and dullness. (1) Glossy; (2) quarter-matte; (3) half-matte; (4) matte; 0, I, II, III and IV are grades of roundness according to Khabakov (1946). 

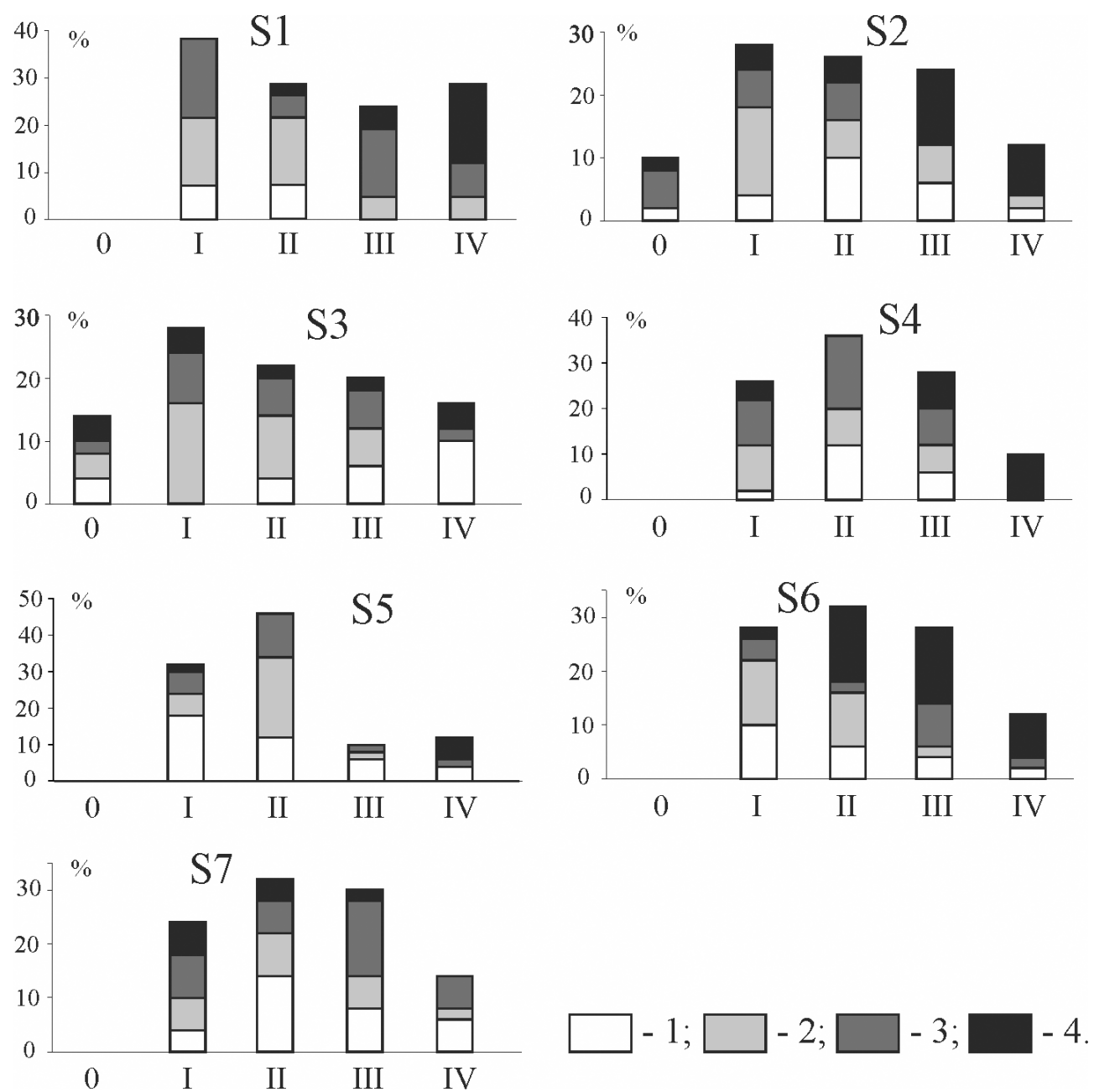

Figure A3. Distribution of quartz sand grains from section NS-13/14 by roundness and dullness. (1) Glossy; (2) quarter-matte; (3) half-matte; (4) matte; 0, I, II, III and IV are grades of roundness according to Khabakov (1946). 

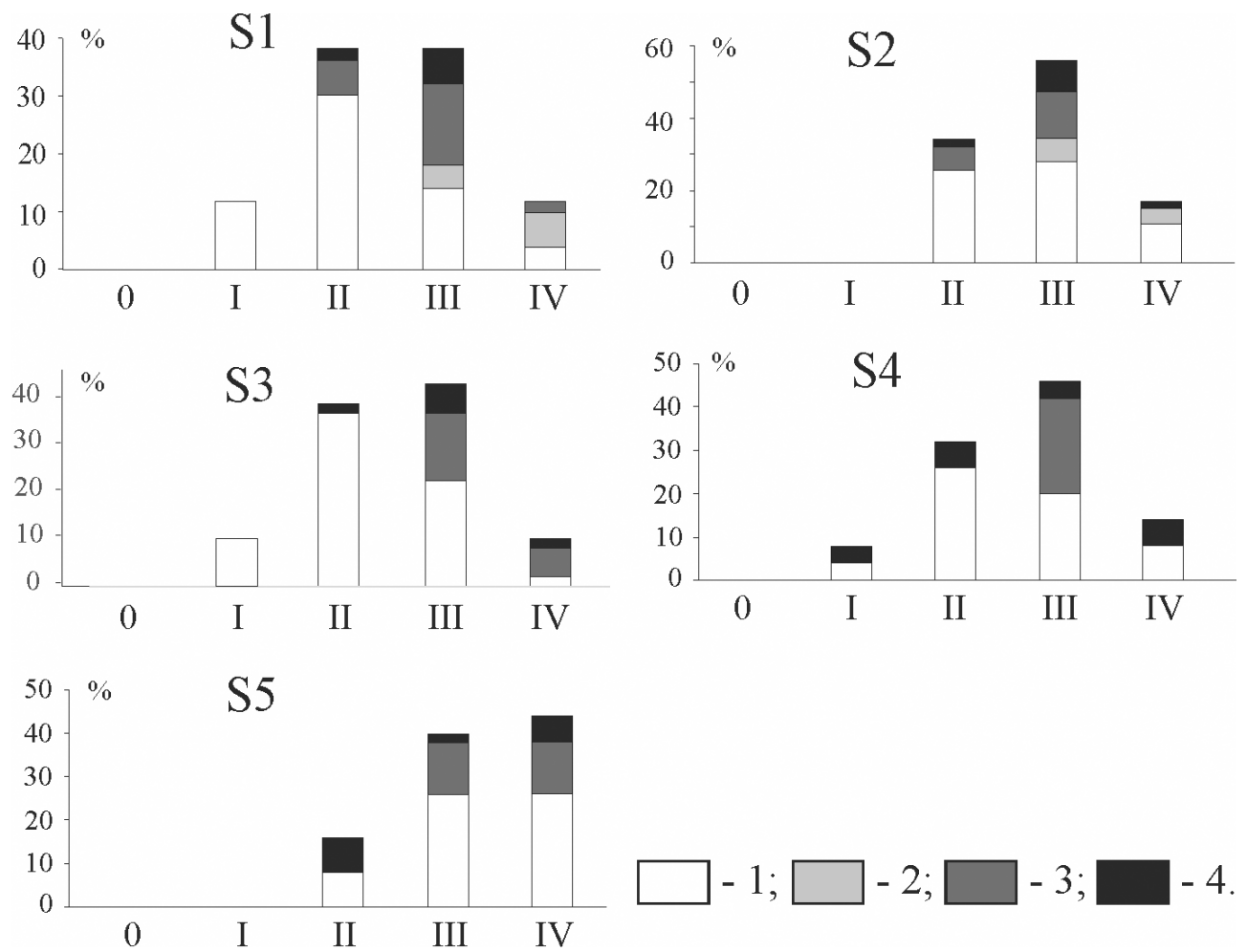

Figure A4. Distribution of quartz sand grains from section NS-20 by roundness and dullness. (1) Glossy; (2) quarter-matte; (3) half-matte; (4) matte; 0, I, II, III and IV are grades of roundness according to Khabakov (1946).

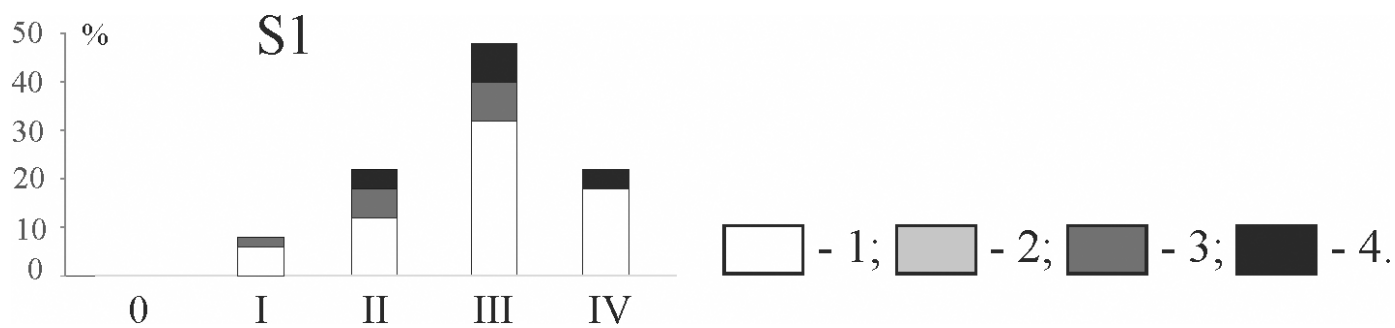

Figure A5. Distribution of quartz sand grains from section NS-22 by roundness and dullness. (1) Glossy; (2) quarter-matte; (3) half-matte; (4) matte; 0, I, II, III and IV are grades of roundness according to Khabakov (1946). 

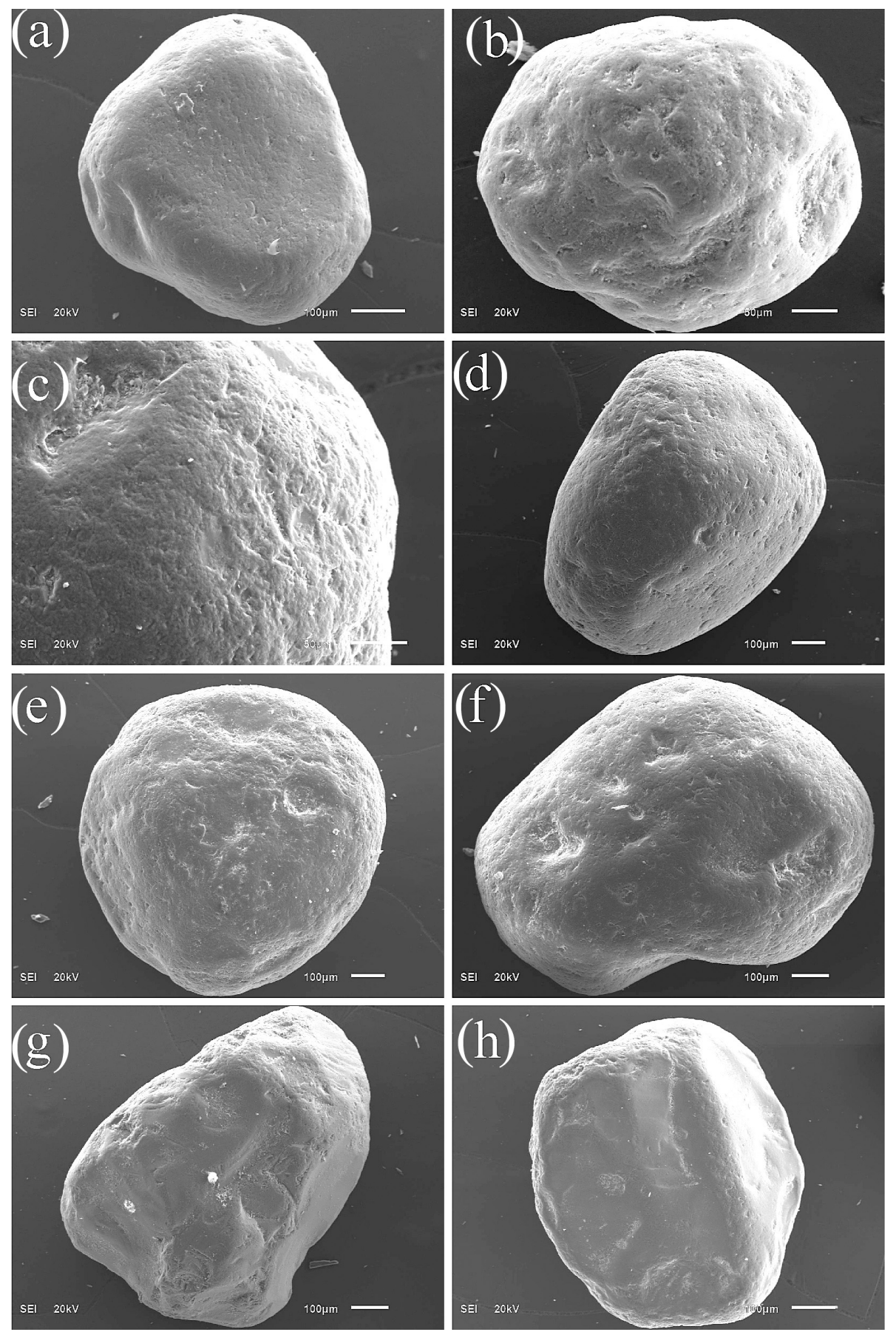

Figure A6. SEM photos of quartz grains, section NS-6. Aeolian sediments: (a) dull grain with a micro-pitted surface and individual crescentshaped depressions; (b) matte grain with a micro-pitted surface and traces of previous subaquatic treatment. Floodplain sediments: (c) halfmatte grain with V-shaped depressions, forming a fine-pitted surface, and with micro-pits; (d) half-matte grain with V-shaped depressions and fine pits. Fluvial deposits: (e) glossy grain with a fine-pitted surface; (f) half-matte grain with a fine-pitted surface and separate V-shaped depressions; (g) glossy grain with fine pits in the protruding parts of the grain; (h) glossy grain with pre-sedimentation fractures, with the surface subjected to aquatic processes, as expressed by the V-shaped depressions. 
(a)

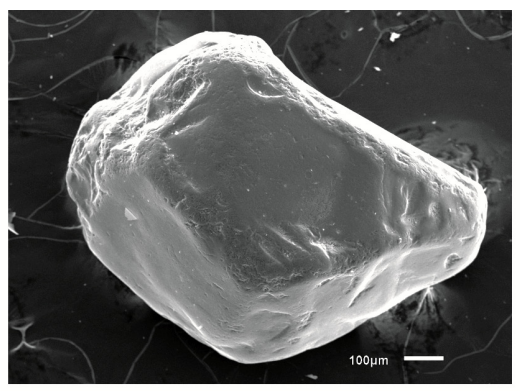

(c)

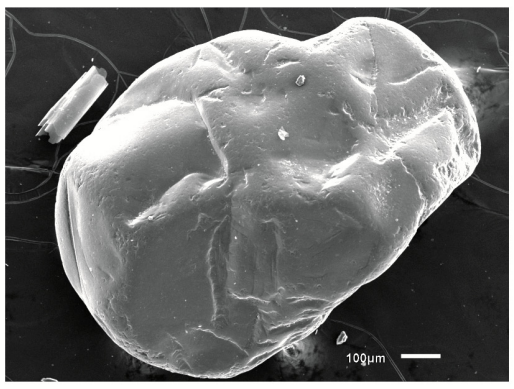

(e)

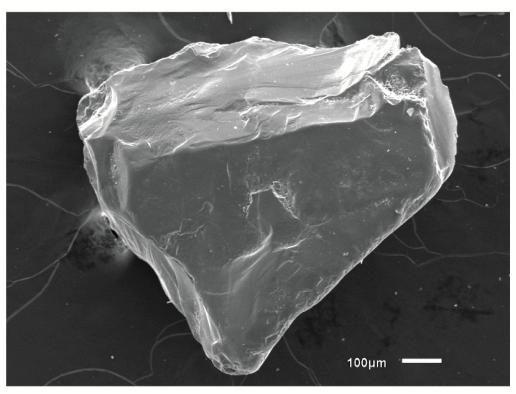

(j)

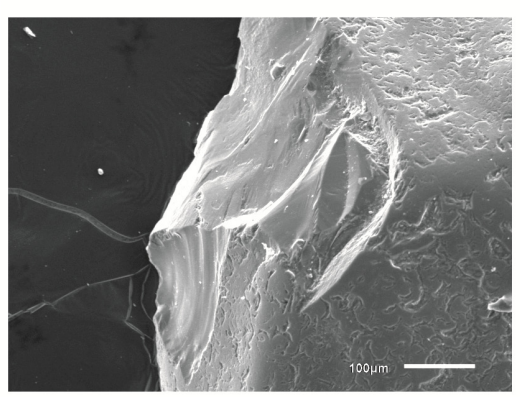

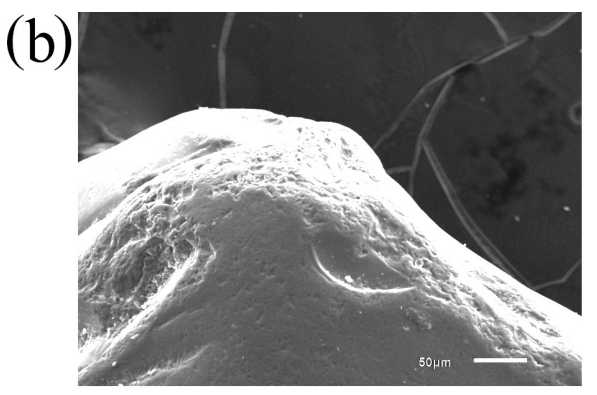

(d)

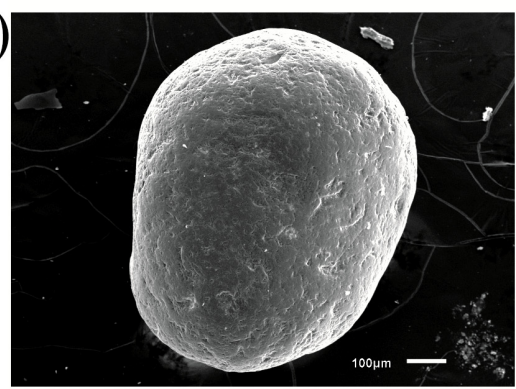

(f)

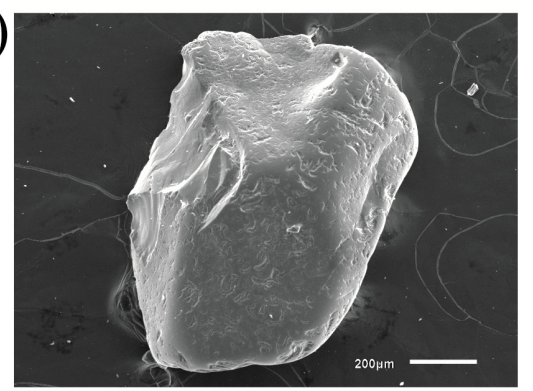

(h)

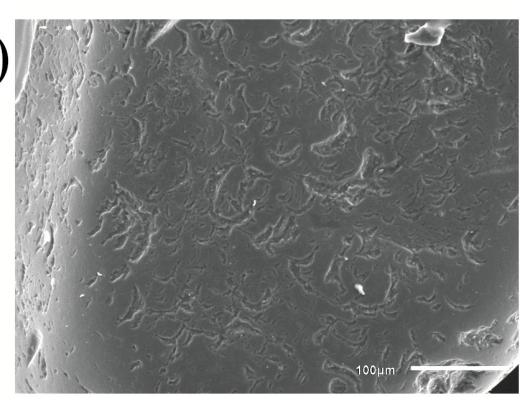

Figure A7. SEM photos of quartz grains from S7 section K-1: (a) glossy grain with a smooth surface and flat faces; the faces feature crescentic pits; grain tops feature fine pits; (b) fine-pitted surface of grain "a"; (c) glossy grain with a smooth surface and sparse fine pits; (d) half-matte grain with fine-pitted surface and crescent pits; (e) glossy grain with flat faces and no evident texture; (f) glossy grain with post-sedimentation conchoidal fractures and crescentic pits; (j) conchoidal fracture of grain "e"; (h) crescentic texture of grain "e". 

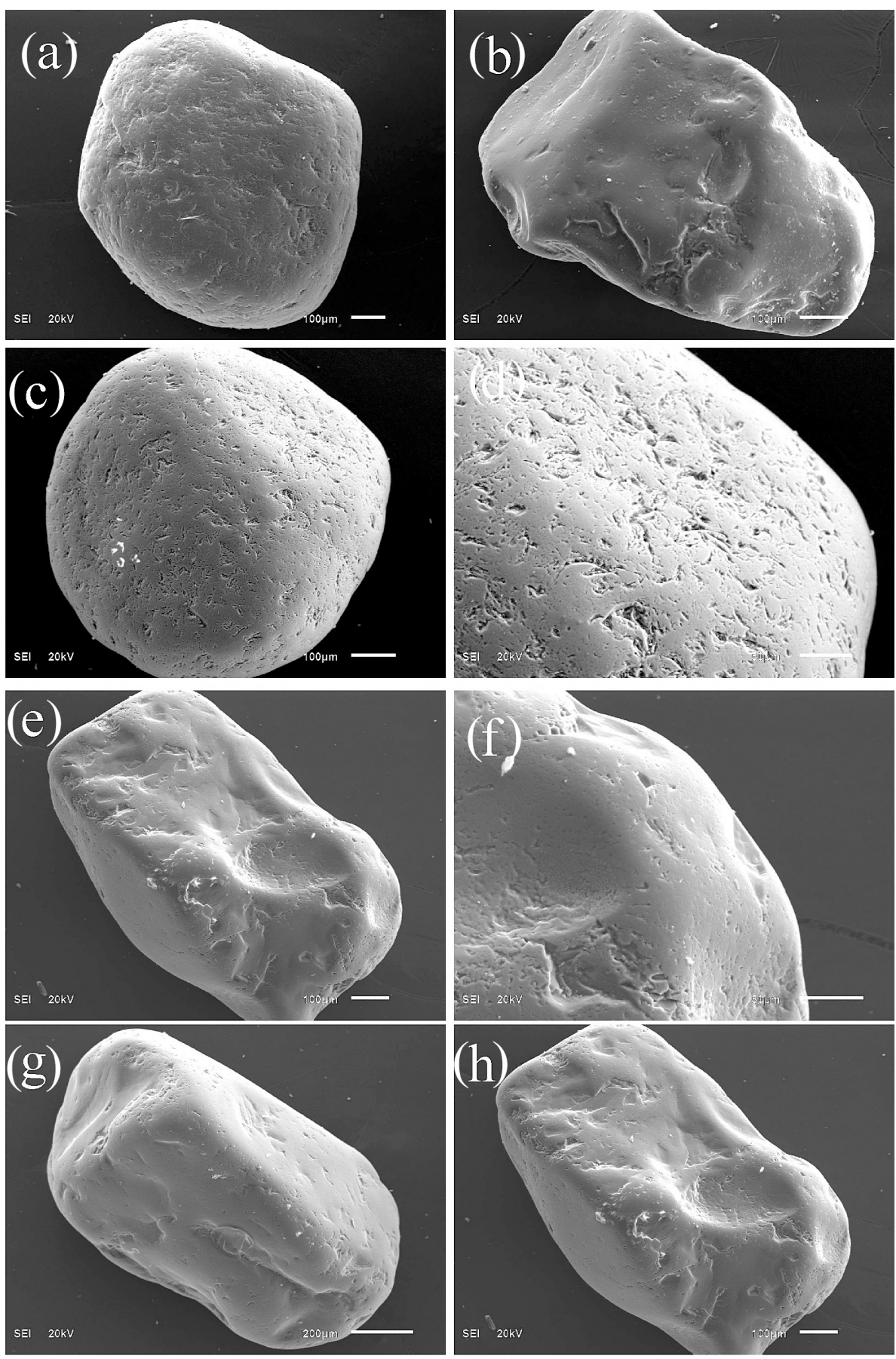

Figure A8. SEM photos of quartz grains from the section NS-13/14: (a) glossy grain with fine-pitted and crescent and V depressions; (b) glossy grain of irregular shape with chips and separate V-shaped recesses; (c, d) half-matte grain with a crescentic texture and micro-pits; (e, f) glossy grain with chips, V shapes, and micro-pits on the protruding parts of the grain; (g) half-matte grain of irregular shape with a fine-pitted texture in the protruding parts of the grain; (h) glossy grain with a conchoidal fracture, $\mathrm{V}$ shapes and fine pits on the protruding parts of the grain. 

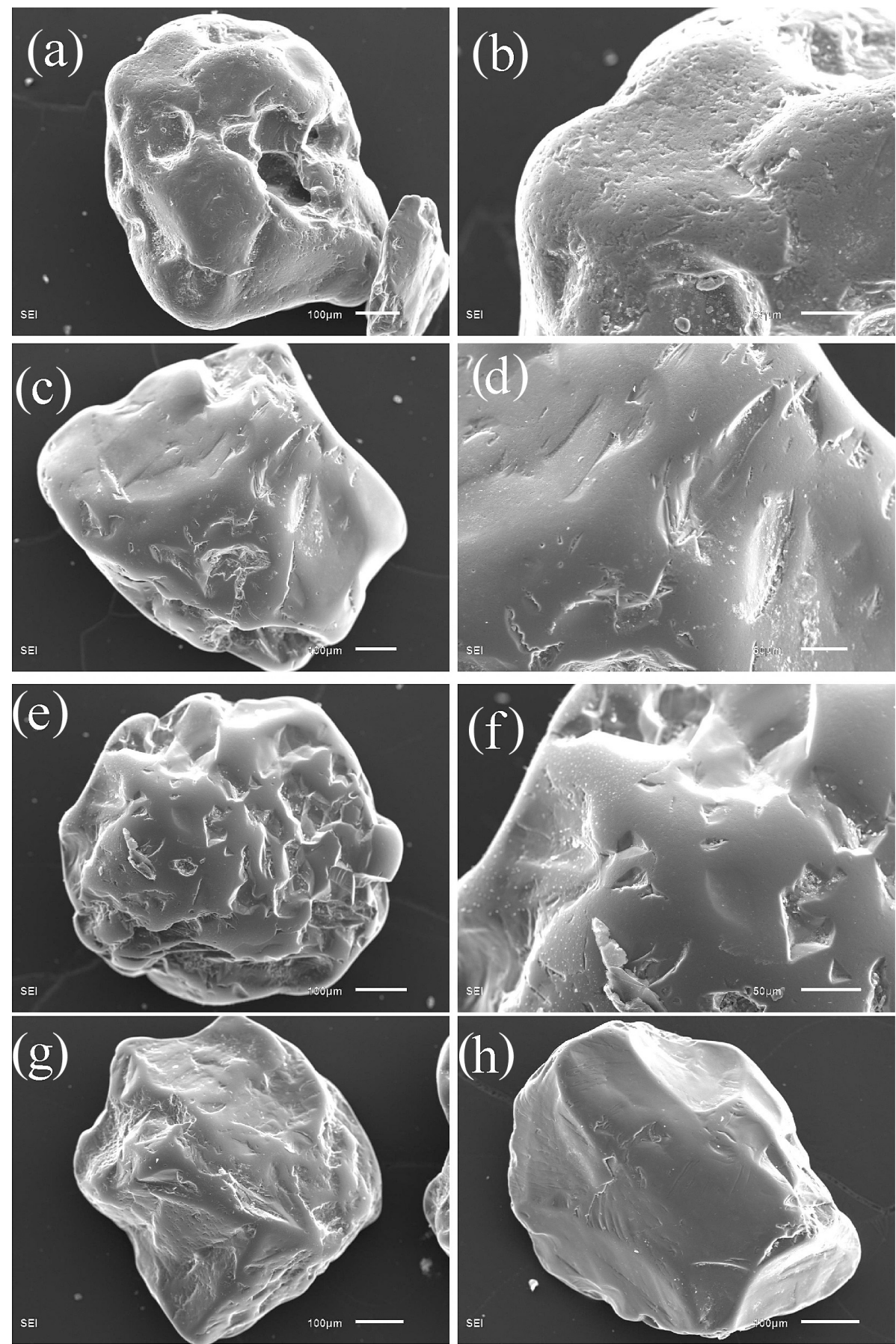

Figure A9. SEM photos of quartz grains from the section NS-20. (a, b) Matte cavernous grain with a micro-pitted surface and individual crescentic and V-shaped percussions; (c, d) glossy grain with a smooth surface, grooves and individual micro-pits; (e, f) glossy grain with deep groove and single V-shaped percussions; (g) glossy grain of irregular shape with separate V-shaped percussions and deep pits; (h) glossy grain with pre-sedimentary conchoidal fractures and scratches. 

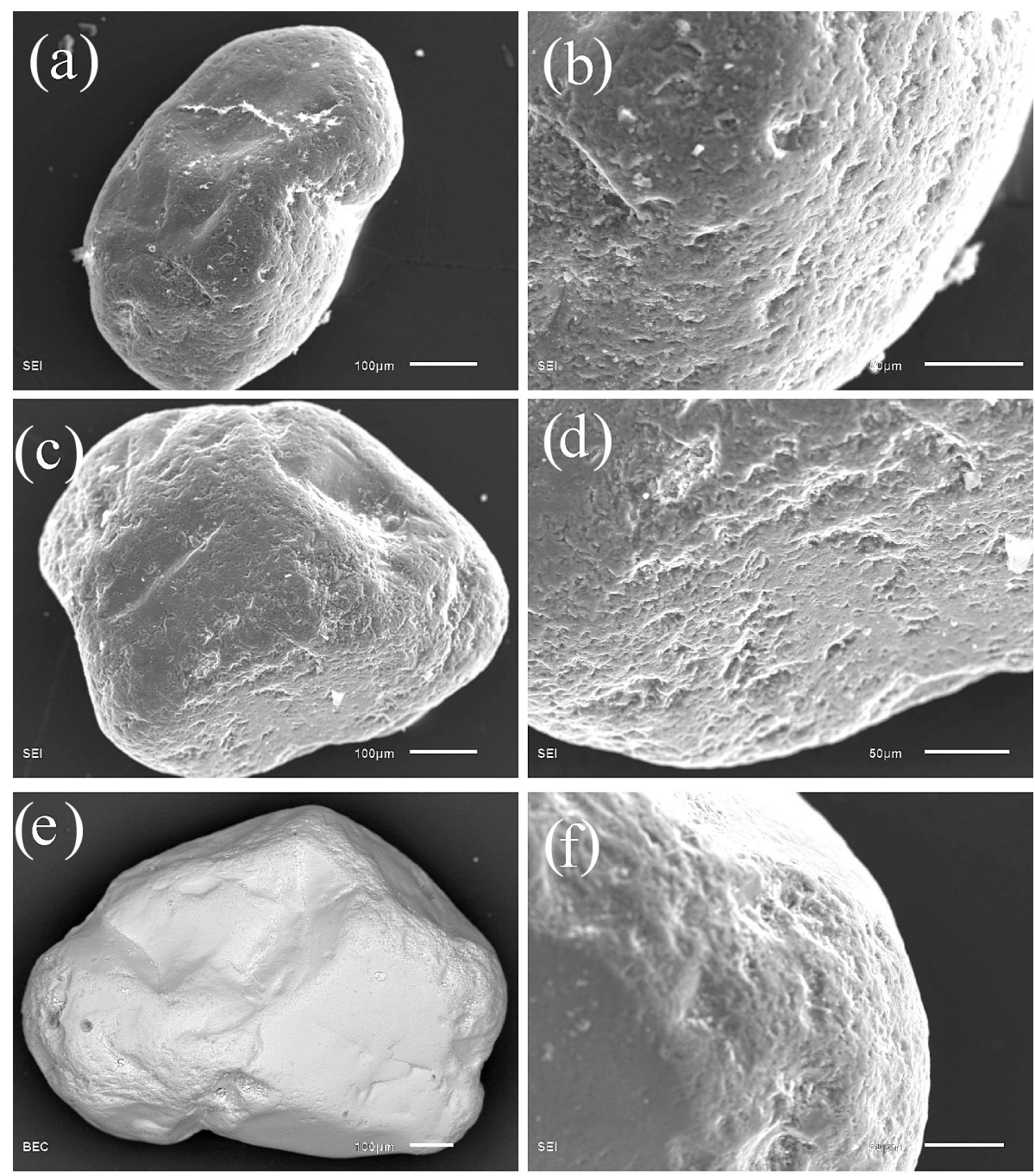

Figure A10. SEM photos of quartz grains from the section NS-22. (a, b) Glossy grain with a fine-pitted surface; (c, d) glossy grain with a fine-pitted surface; (e, f) glossy grain with fine pits on the protruding parts of the grain. 
Data availability. Map layers of Fig. 9 are available in GIS format in Sizov (2020).

Author contributions. OS and AS carried out field work and data interpretation. AVo, AnVi, AnM, OS and As were responsible for laboratory work and data interpretation. EA carried out data processing and interpretation.

Competing interests. The authors declare that they have no conflict of interest.

Acknowledgements. The authors thank the TanDEM-X Science Service System (DLR) for providing the TanDEM-X DEM for research (DEM_GEOL1378). We also thank the reviewers Marc Oliva and Ola Fredin and the editor Arjen Stroeven, whose comments and suggestions helped improve and clarify this paper.

Financial support. This study was funded by the RFBR and the Yamal-Nenets Autonomous District, project number 19-45-890008. The investigation was done under state assignment of the Institute of Geology and Mineralogy, Siberian Branch of the Russian Academy of Sciences.

Review statement. This paper was edited by Arjen Stroeven and reviewed by Marc Oliva and Ola Fredin.

\section{References}

Alyavdin, F. A. and Mokin, N. P.: Geological map. 1rd ed. Scale $1: 1000000$, Ministry of Geology and Subsoil Protection of the USSR, Map Q-43 (Novyy Port.) Gosgeoltekhizdat, Moscow, 1957.

Andreev, Y. F.: About the relationship of linear-ridge topography with tectonic structures in the north of Western Siberia (in the field of permafrost development) Geologiya i geokhimiya, Geol. Geochem., 3, 76-94, 1960.

Astakhov, V. and Nazarov, D.: Correlation of Upper Pleistocene sediments in northern West Siberia, Quaternary Sci. Rev., 29, 3615-3629, 2010.

Astakhov, V., Shkatova, V., Zastrozhnov, A., and Chuyko, M.: Glacio-morphological Map of the Russian Federation, Quaternary Int., 420, 4-14, 2016.

Astakhov, V. I.: On chronostratigraphic units of the Upper Pleistocene in Siberia, Geol. Geofiz., 47, 1207-1220, 2006.

Atkinson, N., Utting, D., and Pawley, S.: Landform signature of the Laurentide and Cordilleran ice sheets across Alberta during the last glaciation, Can. J. Earth Sci., 51, 1067-1083, https://doi.org/10.1139/cjes-2014-0112, 2014

Babushkin, A. E.: Quaternary map, 2rd Edn., Scale 1 : 1000000 , Russian Federation Committee on Geology and Mining (Roskomnedra), Map Q-42, 43 (Salekhard), St. Petersburg, VSEGEI Cartographic Factory, 1996.
Bolikhovskaya, N. S.: Paleoenvironments and climato-stratigraphy of the loess-paleosol formation of Northern Eurasia, 4, 11-36, 2004.

Bolshiyanov, D. Y.: Passive Glaciation of the Arctic and Antarctic Regions, AANII, Saint Petersburg, 296 pp., 2006.

Chekunova, V. S.: Geological and geomorphological survey of a part of the lower reaches of the Nadym River basin and parts of the right bank of the Nadym Ob River, VSEGEI, Leningrad, 74 pp., 1954.

Clark, C., Evans, D., Khatwa, A., Bradwell, T., Jordan, C., Marsh, S., Mitchell, W., and Bateman, M.: Map and GIS database of glacial landforms and features related to the last British ice sheet, Boreas, 33, 359-375, 2004.

Clark, C., Ely, J., Greenwood, S., Hughes, A., Meehan, R., Barr, I., Bateman, M., Bradwell, T., Doole, J., Evans, D., Jordan, C., Monteys, X., Pellicer, X., and Sheehy, M.: BRITICE Glacial Map, version 2: a map and GIS database of glacial landforms of the last British-Irish Ice Sheet, Boreas, 47, 11-27, 2018.

Faibusovich, Y. E. and Abakumova, L. A.: Map of PlioceneQuaternary formations, 3rd Edn., Scale 1:1000000, Federal Agency for Subsoil Use (Rosnedra), Map Q-43 (New Urengoy.) St. Petersburg, VSEGEI Cartographic Factory, 2015.

Fredin, O., Rubensdotter L., Welden, A., Larsen, E., and Lysa, A.: Distribution of ice marginal moraines in NW Russian, J. Maps, 8, 236-241, https://doi.org/10.1080/17445647.2012.708536, 2012.

Generalov, P. P.: Upper Pleistocene of the lower course of the $\mathrm{Ob}$ River In: Collection of scientific papers of the West Siberian Scientific and Research Geological Prospecting Petroleum Institute, Tyumen, 56-77, 1986.

Glasser, N., Jansson, K., Harrison, S., and Kleman, J.: The glacial geology and Pleistocene history of South America between 38,8S and 56,8S, Quaternary Sci. Rev., 27, 365-390, 2008.

Grosvald, M. G.: Eurasian Hydrospheric Catastrophes and Glaciations of the Arctic Region, Nauchny Mir, Moscow, 120 pp., 1999.

Groysman, Y. M.: Geological survey of the Haigi-Yakh River basin (Long-Yugan), VSEGEI, Leningrad, 200 pp., 1954.

Immonen, N., Strand, K., Huusko, A., and Lunkka, J. P.: Imprint of late Pleistocene continental processes visible in ice-rafted grains from the central Arctic ocean, Quaternary Sci. Rev., 92, 133-139, 2014.

Kalinska-Nartisa, E., Woronko, B., and Ning, W.: Microtextural inheritance on quartz sand grains from Pleitocene periglacial environments of the Mazovian Lowland, Central Poland, Permafrost Periglac., 28, 741-756, 2017.

Khabakov, A. V.: On roundness indexes of pebble, Sovetskaya Geologiya, 10, 98-99, 1946.

Khlebnikov, V. I.: Geological and geomorphological survey of a part of the middle reaches of the Nadym river basin, VSEGEI, Leningrad, 192 pp., 1954.

Kind, N. V.: Late Quaternary Geochronology According to Isotope Data, Nauka, Moscow, 255 pp., 1974.

Krinsley, D. H. and Doornkamp, J. C.: Atlas of quartz sand surface textures, 2nd Edn., Cambridge, Cambridge University Press, 102, 91 pp., 2011.

Lazukov, G. I.: Antopogen of the northern part of Western Siberia (Paleogeorgaphy), Moscow, 127 pp., 1972.

Maslennikov, V. V.: Regional Geo-Ecological Mapping at Scale of $1: 1000000$ Within the North End of Tyumen Oblast, Labytnangi, FGU NPP “Aerogeology”, 50 pp., 1998. 
Molodkov, A.: Cross-check of the dating results obtained by ESR and IR-OSL methods: implication for the Pleistocene palaeoenvironmental reconstructions, Quat. Geochronol., 10, 188-194, 2012.

Molodkov, A.: The Late Pleistocene palaeoenvironmental evolution in Northern Eurasia through the prism of the mollusc shellbased ESR dating evidence, Quaternary Int., 556, 180-197, https://doi.org/10.1016/j.quaint.2019.05.031, 2020.

Molodkov, A. and Bitinas, A.: Sedimentary record and luminescence chronology of the Lateglacial and Holocene aeolian sediments in Lithuania, Boreas, 35, 244-254, 2006.

Molodkov, A. and Bolikhovskaya, N.: Climato-chronostratigraphic framework of Pleistocene terrestrial and marine deposits of Northern Eurasia based on pollen, electron spin resonance, and infrared optically stimulated luminescence analyses, Est. J. Earth Sci., 59, 49-62, 2010.

Norris, S. L., Margold, M., and Froese, D. G.: Glacial landforms of northwest Saskatchewan, J. Maps, 13, 600-607, https://doi.org/10.1080/17445647.2017.1342212, 2017.

Rukhin, L. B.: Fundamentals of Lithology, Doctrine of Sedimentary Rocks, Nedra, Leningrad, 703 pp., 1969.

Rusakov, A., Sedov, S., Sheinkman, V., Dobrynin, D., Zinovyev, E., Trofimova, S., and Levchenko, S.: Late Pleistocene paleosols in the extra-glacial regions of Northwestern Eurasia: Pedogenesis, post-pedogenic transformation, paleoenvironmental inferences, Quaternary Int., 501, 174-192, https://doi.org/10.1016/j.quaint.2018.03.020, 2018.

Sedov, S., Rusakov, A., Sheinkman, V., and Korkka, M.: MIS3 paleosols in the center-north of Eastern Europe and Western Siberia: Reductomorphic pedogenesis conditioned by permafrost?, Catena, 146, 38-47, https://doi.org/10.1016/j.catena.2016.03.022, 2016.

Sharpe, J., Sharpe, D., and Harris J.: A flowline map of glaciated Canada based on remote sensing data, Can. J. Earth Sci., 47, 89$101,2010$.

Sheinkman, V., Sedov, S., Shumilovskikh, L., Korkina, E., Korkin, S., Zinovyev, E., and Golyeva, A.: First results from the Late Pleistocene paleosols in northern Western Siberia: Implications for pedogenesis and landscape evolution at the end of MIS3, Quaternary Int., 418, 132-146, https://doi.org/10.1016/j.quaint.2015.12.095, 2016.

Sizikova, A. O. and Zykina V. S.: The dynamics of the Late Pleistocene loess formation, Lozhok section, Ob loess Plateau, SW Siberia, Quaternary Int., 365, 4-14, 2015.

Sizov, O.: Glacial and fluvioglacial relief interpretation in the middle course of the Nadym River, Mendeley Data, V1, https://doi.org/10.17632/7trbspbwgd.1, 2020.

Strelkov, S. A., Saks, V. N., Arkhipov, S. A., and Volkova, V. S.: The problem of the Quaternary glaciations of Siberia, The main problems of the study of the Quaternary period, Nauka, Moscow, 188-205, 1965.
Sukhorukova, S. S., Kostyuk, M. A., Podsosova, L. L., Babushkon, A. E., Zolnikov, I. D., Abramova, S. A., and Goncharov, S. V.: Moraines and Dynamics of Glaciation in Western Siberia. Works of Institute of Geology and Geochemistry of the Siberian Branch of the USSR Academy of Sciences, Issue 672, Nauka, Novosibirsk, 159 pp., 1987.

Svendsen, J., Alexahderson, H., Astakhov, V., Demidov, I., Dowdeswell, Ju., Funder, S., Gataulin, V., Henriksen, M., Hjort,H., Houmark-Nielsen, M., Hubberten, H.-W., Ingolfsson, O.,Jakobsson, M., Kjar, K., Larsen, E., Lokrantz, H., Lunkka, Ju. P.,Lysa, A., Mangerud, J., Matiouchkov, A., Murray, A., Moller, P., Niessen, F., Nikolskaya, O., Polyak, L., Saarnisto, M., Siegert, Ch., Siegert, M., Spielhagen, R., and Stein, R.: Late Quaternary ice sheet history of Northern Eurasia, Quaternary Sci. Rev., 23, 1229-1271, 2004.

Troitskiy, S. L. and Shumilova, E. V.: Stratigraphy and Mineralogical-Petrographic Peculiarities of Quaternary Deposits in the Vorontsov Yar Stratum in the Lower Course of the Yenisei River. In: Lithology and Conditions of Formation of the Quaternary Deposits of the Northern Eurasia, Institute of Geology and Geochemistry of the Siberian Branch of the USSR Academy of Sciences, Novosibirsk, 5-37, 1974.

Vasilyev, S. V.: Forest and Bog Landscapes of Western Siberia, Izdatelstvo NTL, Tomsk, 276 pp., 2007.

Velichko, A. A.: Current state of conceptions on continental glaciers of the Earth, Bull. Acad. Sci. USSR, 3, 21-34, 1987.

Velichko, A. A. and Timireva S. N.: Morphoscopy and morphometry of quartz grains from loess and buried soil layers, Geo. J., 36, 143-149, 1995.

Velichko, A. A., Timireva, S. N., Kremenetski, K. V., McDonald, G. M., and Smith, L. C.: West Siberian Plain as a late glacial desert, Quaternary Int., 237, 45-53, 2011.

Velichko, A. A., Konononv, V. M., and Faustova M. A.: The last glaciation of Earth: size and volume of ice-sheets, Quaternary Int., 41, 43-51, 1997.

Vos, K., Vandenberghe, N., and Elesen, J.: Surface textural analysis of quartz grains by scanning electron microscopy (SEM): From sample preparation to environmental interpretation, EarthSci. Rev., 128, 93-104, 2014.

Woronko, B.: Frost weathering versus glacial grinding in the micromorphology of quartz sand grains: Process and geological implications, Sediment. Geol., 335, 103-119, 2016.

Yevseyev, G. P. and Reynin, I. V.: Geological structure and geomorphology of the Tanlova, Right Khetta, and Big Huhu basins (right tributaries of the middle segment of the Nadym river), VNIGRI, Leningrad, 72 pp., 1958.

Zemtsov, A. A.: Geomorphology of the West Siberian Plain (Northern and Central Parts), Publishing house of the Tomsk State University, Tomsk, 344 pp., 1976.

Zhamoida, A. I.: General Stratigraphic Scale of Russia: State of the art and problems, Russian Geol. Geophys., 56, 511-523, https://doi.org/10.1016/j.rgg.2015.03.003, 2015. 